Revista PSICOLOGIA, 2021, Vol 35 (1), 95-146. doi: 10.17575/psicologia.v35i1.1727

\title{
0 diabo está nos pormenores: Introdução às normas para escrita científica da American Psychological Association (7ª edição)
}

Marília Prada ${ }^{1}$, Cristina Camilo ${ }^{1}$, Margarida Vaz Garrido ${ }^{1}$ \& David L. Rodrigues ${ }^{1}$

${ }^{1}$ ISCTE-Instituto Universitário de Lisboa, CIS-IUL, Lisboa, Portugal

\begin{abstract}
Resumo: 0 principal objetivo deste artigo é sintetizar as principais normas de escrita científica definidas na 7ํa edição do Publication Manual da American Psychological Association (APA, 2020). Especificamente, iremos focar as recomendações relativas à estrutura e conteúdos de um manuscrito, formatação do texto, citações e referências bibliográficas. Este artigo destina-se a estudantes e investigadores que estão a iniciar a sua atividade de escrita científica, mas também a investigadores familiarizados com a versão anterior do Publication Manual da APA. Para tal, e com vista a facilitar a integração destas novas recomendações, iremos também sistematizar as principais diferenças entre estas últimas edições.
\end{abstract}

Palavras-chave: Regras APA; escrita científica; formatação; referências bibliográficas; citações

The devil is in the details: Introduction to the scientific writing guidelines of the American Psychological Association ( $7^{\text {th }}$ ed.): The main goal of this paper is to summarize the main guidelines of scientific writing presented in the $7^{\text {th }}$ edition of the Publication Manual of the American Psychological Association (APA, 2020). Specifically, we will focus on the recommendations regarding the structure and content of a manuscript, formatting styles, citations, and references. This paper is useful for students and researchers who are initiating scientific writing and researchers trained to use the previous edition of the Publication Manual. In particular, to facilitate the integration of the revised guidelines, we will also systematize the main differences between the last two editions.

Keywords: APA guidelines; scientific writing, formatting, references, citations

Nota: A formatação deste artigo pretende exemplificar as recomendações da APA para submissão de manuscritos (à exceção da folha de rosto, ver Figura 1, e do resumo), distinguindo-se assim da formatação habitual da Revista PSICOLOGIA.

1 Morada para correspondência: Marília Prada, Instituto Universitário de Lisboa (ISCTE-IUL), Av. das Forças Armadas, gabinete AA.110, 1649-
026 Lisboa, Portugal. E-mail: marilia_prada@iscte-iul.pt 
NORMAS DE ESCRITA CIENTÍFICA (APA, 7ạ EDIÇÃO)

\section{O Diabo Está nos Pormenores: Introdução às Normas de Escrita Científica da American Psychological Association (7ª edição)}

Aprender as "normas da APA" é um dos desafios que se coloca a muitos estudantes, particularmente nas áreas das ciências sociais e humanas, desde o momento em que ingressam no ensino superior. Especificamente, no caso da Psicologia, a influência destas normas é incontornável, sendo habitual pedir aos estudantes que utilizem as diretrizes de formatação e referências bibliográficas na preparação dos trabalhos. Ainda que da nossa experiência enquanto docentes este não seja um dos tópicos mais populares, dominar o estilo APA é uma ferramenta essencial para estudantes de todos os ciclos de estudos, bem como para os investigadores de diferentes áreas. Ao longo deste trabalho iremos discutir um conjunto de recomendações, em alguns casos gerais, noutros pormenorizadas (e.g., quando usar itálico), que tornam evidente porque é que "o Diabo está nos detalhes". Apesar da dificuldade inicial, através do treino, vamos integrando as diferentes normas e aplicando-as de forma automatizada.

Quando falamos de normas da APA referimo-nos às recomendações expressas no Publication Manual da American Psychological Association. A primeira versão remonta há cerca de 90 anos (Bentley, 1929) e consistia num breve documento de sete páginas que visava definir orientações para a preparação de artigos científicos. Desde então, o manual tem vindo a ser reformulado e atualizado de forma a corresponder às novas práticas de investigação e de disseminação de conhecimento científico, bem como a novas realidades sociais. Na última década, tem sido utilizada a sexta edição do manual, publicada em 2010, em diferentes esferas do contexto académico. De forma a facilitar a compreensão das recomendações pelo público nacional, publicámos uma versão resumida dessa edição (para revisão, ver Prada \& Garrido, 2013). Dado que foi recentemente publicada a sétima edição do manual (2020), é pertinente atualizar as normas. Assim, neste artigo, iremos descrever as principais recomendações da APA no que diz respeito à preparação de manuscritos (e.g., regras de estrutura e de formatação) e de reconhecimento das fontes utilizadas na sua preparação (e.g., citações ao longo do texto e referências bibliográficas). 
NORMAS DE ESCRITA CIENTÍFICA (APA, 7ạ EDIÇÃO)

Salientamos que apenas iremos descrever as normas definidas na edição em vigor sistematizando as diferenças entre a versão atual e a anterior (APA, 2010, 2020, respetivamente) em Anexo.

Um equívoco comum é que o manual da APA apenas se prende com detalhes relativos a formatação e referências bibliográficas. Porém, nas mais de 400 páginas que integram a versão atual, são discutidos muitos outros aspetos relativos a boas práticas de investigação e disseminação de conhecimento científico. Sempre que relevante, identificamos em que capítulos da sétima edição do manual o leitor pode aprofundar alguns tópicos, referenciando ainda outros recursos complementares. Por exemplo, os leitores interessados nos aspetos éticos poderão consultar o primeiro capítulo do manual ("Scholarly Writing and Publishing Principles", pp. 3-28), bem como o capítulo sobre "Ética em Contexto Académico" de Moleiro e Collins (2016).

De uma forma geral, podemos definir que o principal objetivo do manual consiste em fornecer recomendações para uma comunicação clara, concisa e precisa. Ao partilharmos um manual de estilo, potenciamos a uniformização e consistência na comunicação. Tal permite ao leitor focar-se nas principais ideias a serem transmitidas, evidências apresentadas e fontes consultadas (APA, 2020). Um ponto central destas orientações é a eliminação de enviesamentos na forma como comunicamos (ver Capítulo 5 - “Bias-Free Language Guidelines”, pp. 131-152). Isto é particularmente aplicável à forma como descrevemos determinadas características de grupos sociais (e.g., idade, género, identidade racial ou étnica). Alguns exemplos incluem a sugestão de substituição de adjetivos por frases descritivas de um determinado grupo (e.g., "pessoas em situação de pobreza" em vez de "os pobres", ou "pessoas portadoras de deficiência" em vez de "os deficientes"). Porém, é de notar que alguns mecanismos linguísticos para evitar este tipo de viés não são diretamente aplicáveis à língua portuguesa. Um exemplo é a sugestão de utilização de pronomes neutros em relação ao género ("a researcher career depends on how often they are cited" em vez de "a researcher career depends on how often he or she are cited"). Ainda assim, devemos sempre certificarmo-nos que utilizamos os termos mais consensualmente aceites pelo grupo a que nos referimos. Para tal, poderá ser necessário consultar organizações que representem ou trabalhem 
NORMAS DE ESCRITA CIENTÍFICA (APA, 7ạ EDIÇÃO)

diretamente com esses grupos. Outra recomendação geral para a escrita científica é o evitamento de ambiguidade a todos os níveis, desde a descrição de conceitos à descrição dos participantes ou dos resultados. Por exemplo, em vez de categorias abrangentes (e.g., "idosos”; "maiores de 65 anos") devemos incluir o intervalo específico a que nos referimos (e.g., "pessoas com idades compreendidas entre os 65 e os 85 anos"). Apesar do cuidado crescente em tornar o manual um documento abrangente, que aborda todas as questões ligadas ao desenvolvimento e reporte da investigação, são as questões formais de estruturação e formatação do texto que habitualmente recebem maior atenção por parte dos leitores.

\section{Formato, Estrutura e Conteúdos de um Manuscrito}

Os manuscritos podem conter diferentes elementos, dependendo da sua tipologia (e.g., artigo teórico, empírico ou metodológico - ver Capítulo 1 - "Scholarly Writing and Publishing Principles", pp. 3-28) e do seu propósito (e.g., publicação científica ou trabalho para uma unidade curricular). Por exemplo, um manuscrito preparado com vista à submissão a uma revista científica contém habitualmente: página de título (i.e., título do trabalho, nome e afiliação dos autores, nota dos autores); resumo acompanhado por palavras-chave; corpo do texto (organizado em diferentes secções, com páginas numeradas, com ou sem tabelas e figuras, e notas de rodapé); lista de referências e, se necessário, anexos. Porém, poderá haver discrepâncias tanto ao nível da organização, como da formatação do manuscrito, consoante o manual de estilo de cada revista. ${ }^{2}$ Já os manuscritos que constituem trabalhos de estudantes (e.g., relatórios, revisões de literatura sobre determinado tema ou área, teses ou dissertações) incluem habitualmente elementos como: página de título (incluindo nome e número de aluno, identificação da unidade curricular e do docente), corpo do texto e lista de referências. Obviamente que diferentes instituições podem adotar regras

\footnotetext{
2 Por exemplo, revistas classificadas no domínio da Psicologia, como o Journal of Personality and Social Psychology editado pela própria APA ou a Revista PSICOLOGIA editada pela Associação Portuguesa de Psicologia, apresentam recomendações congruentes com as que aqui sumariamos. Já revistas multidisciplinares como a Appetite, apesar de genericamente seguirem o estilo APA (e.g., referências e citações no texto), apresentam algumas diferenças, nomeadamente ao nível do sistema de títulos requerido (para exemplo de instruções para autores, ver https://www.elsevier.com/journals/appetite/0195-6663/guidefor-authors).
} 
NORMAS DE ESCRITA CIENTÍFICA (APA, 7ạ EDIÇÃO)

divergentes das definidas pelo estilo APA (e.g., inclusão do logótipo da universidade na página de título). ${ }^{3}$ Tendo em conta potenciais variações de estrutura requeridas por diferentes instituições, ou mesmo docentes, descrevemos de seguida apenas os elementos definidos pelo estilo APA.

A Tabela 1 sistematiza aspetos gerais de formatação do manuscrito.

\section{Tabela 1}

Aspetos Gerais de Formatação de Manuscritos

\begin{tabular}{ll}
\hline & Formato \\
\hline $\begin{array}{l}\text { Tipo de letra } \\
\text { (tamanho) }\end{array}$ & $\begin{array}{l}\text { Calibri (11), Arial (11), Lucida Sans Unicode (10), Times New Roman (12), Georgia } \\
\text { (11) ou Computer Modern (10). No caso de tabelas e figuras, o tamanho da letra } \\
\text { poderá variar de modo a potenciar a legibilidade (8 a 14 pontos). }\end{array}$ \\
Espaçamento & Duplo (no caso das tabelas, o espaçamento poderá ser simples, 1.5 linhas ou duplo) \\
Margens & $2.54 \mathrm{~cm}$ em todos os lados (predefinição dos processadores de texto) \\
Alinhamento & Texto alinhado à esquerda (exceções assinaladas nas respetivas secções) \\
Avanço do texto & $1.27 \mathrm{~cm}$ na primeira linha de cada parágrafo (predefinição dos processadores de \\
& texto, tecla "tab") \\
\hline
\end{tabular}

\section{Página de Título}

Os elementos das páginas de título encontram-se sistematizados na Tabela 2 e ilustrados na

Figura 1.

\section{Tabela 2}

Página de Título: Elementos e Formatação

\begin{tabular}{|c|c|}
\hline Elemento & Descrição \\
\hline $\begin{array}{l}\text { (A) Número de } \\
\text { página }\end{array}$ & A página de título corresponde à página 1 . \\
\hline $\begin{array}{l}\text { (B) Cabeçalho } \\
\text { ("Running } \\
\text { Head") }\end{array}$ & $\begin{array}{l}\text { Forma abreviada do título do trabalho (até } 50 \text { caracteres, incluindo letras, pontuação e } \\
\text { espaços entre palavras). }\end{array}$ \\
\hline $\begin{array}{l}\text { Título do } \\
\text { trabalho }\end{array}$ & $\begin{array}{l}\text { O título deve sumariar a ideia principal do manuscrito (i.e., principal tópico de investigação, } \\
\text { identificando as variáveis ou aspetos teóricos em estudo e a relação entre estes), se possível } \\
\text { de forma a envolver os leitores. } \\
\text { Ainda que não seja definido um tamanho máximo, é recomendado que o título seja o mais } \\
\text { simples e conciso possível. Termos (ou expressões) genéricos, como "um estudo } \\
\text { experimental sobre..." devem ser evitados porque apenas contribuem para tornar o título }\end{array}$ \\
\hline
\end{tabular}

\footnotetext{
${ }^{3}$ Por exemplo, o Iscte-Instituto Universitário de Lisboa define normas orientadoras para a preparação de teses e dissertações (https://www.iscte-

iul.pt/assets/files/2020/07/14/1594736316665_Iscte_Normas_Graficas_2020.pdf)
} 
(C) Autoria

(D) Afiliação

(E) Nota dos autores mais extenso, não potenciando a identificação dos artigos em bases de dados bibliográficas (e.g., PsycINFO).

Para reduzir a probabilidade de confusão na identificação de autores, a forma preferencial é nome próprio, inicial do nome do meio e apelido (e.g., Margarida V. Garrido). Os autores devem ser consistentes na forma como se identificam. Cargos e títulos profissionais ou académicos são omitidos (e.g., Professor, PhD).

Caso existam múltiplos autores, devem ser ordenados de acordo com a sua contribuição para o trabalho.

Refere-se à instituição em que o autor trabalhava (ou estudava) quando o trabalho foi conduzido. Apenas se inclui afiliação dupla quando duas instituições contribuíram substancialmente para suportar o estudo. Se a afiliação mudou desde que o trabalho foi completado, deverá indicar-se a nova afiliação em "nota dos autores".

No caso de afiliações académicas, incluir o nome do departamento e da instituição separados por vírgula (e.g., Departamento de Psicologia da Educação, ISPA-Instituto Universitário), dispensando o local (a não ser que faça parte do nome da instituição). Já as afiliações não-académicas (e.g., hospitais não afiliados a uma universidade, laboratórios independentes, etc.) requerem a identificação do nome do departamento, da instituição e o local (e.g., Departamento de Psicologia, Hospital Lusíadas, Lisboa, Portugal).

Fornece informação adicional acerca dos autores ou do estudo, bem como fontes de financiamento e potenciais fontes de conflito de interesses. Organizado em parágrafos (nenhum obrigatório, na ordem seguinte):

1. Nome do autor e ORCID ${ }^{a}$ (ver Figura 1)

2. Eventuais alterações de afiliação

"Rita Silva encontra-se atualmente na Universidade de Colónia."

3. Divulgação de informação (Disclosures) e Agradecimentos (se breve, combinar num único parágrafo), nomeadamente:

3a) Pré-registo: se o estudo foi pré-registado incluir o nome da plataforma e respetivo número.

3b) Acesso dados/materiais: Se dados ou materiais do estudo estão disponíveis com a publicação do artigo.

3c) Publicações anteriores e conflito de interesses: caso o artigo se baseie em dados já publicados, esse trabalho deve ser incluído na lista de referências

Este artigo baseia-se em dados publicados por Lopes (2012).

Indicar (potenciais) conflitos de interesse (e.g., um dos autores é acionista do fabricante do medicamento testado).

3d) Reconhecimento de fontes de financiamento (incluindo entidade financiadora, referência da bolsa e quem a recebeu) ou outros apoios (pessoas, para além dos autores, que colaboraram em algum aspeto do estudo como recolha de dados ou edição).

“Este estudo foi financiado pela Fundação para a Ciência e Tecnologia (PD/BD/135440/2017) através de uma bolsa atribuída a C. Possidónio"; "Os autores gostariam de agradecer à ILGA Portugal e Rede Ex-Aequo pela ajuda na disseminação do estudo, através da partilha do link para o estudo nas suas páginas web."

4. Informação de contacto (corresponding author): um dos autores (habitualmente o primeiro) fica responsável por responder a eventuais questões sobre o trabalho após publicação e por preservar os dados durante o período necessário. Incluir o nome e morada completa, separados por vírgula, seguido pelo endereço de email (ver Figura 1).

Nota. Para ilustração de cada secção ver Figura 1. Cada elemento corresponde a uma caixa de texto (identificada com uma letra) onde são apresentados aspetos de formatação.

${ }^{a}$ Trata-se de um identificador digital único e permanente (código numérico) que distingue um investigador de outro, resolvendo assim o problema da ambiguidade e semelhança de nomes de autores (https://orcid.org/). 
NORMAS DE ESCRITA CIENTÍFICA (APA, 7ạ EDIÇÃO)

\section{Figura 1}

Ilustração da Formatação dos Diferentes Elementos de uma Página de Título

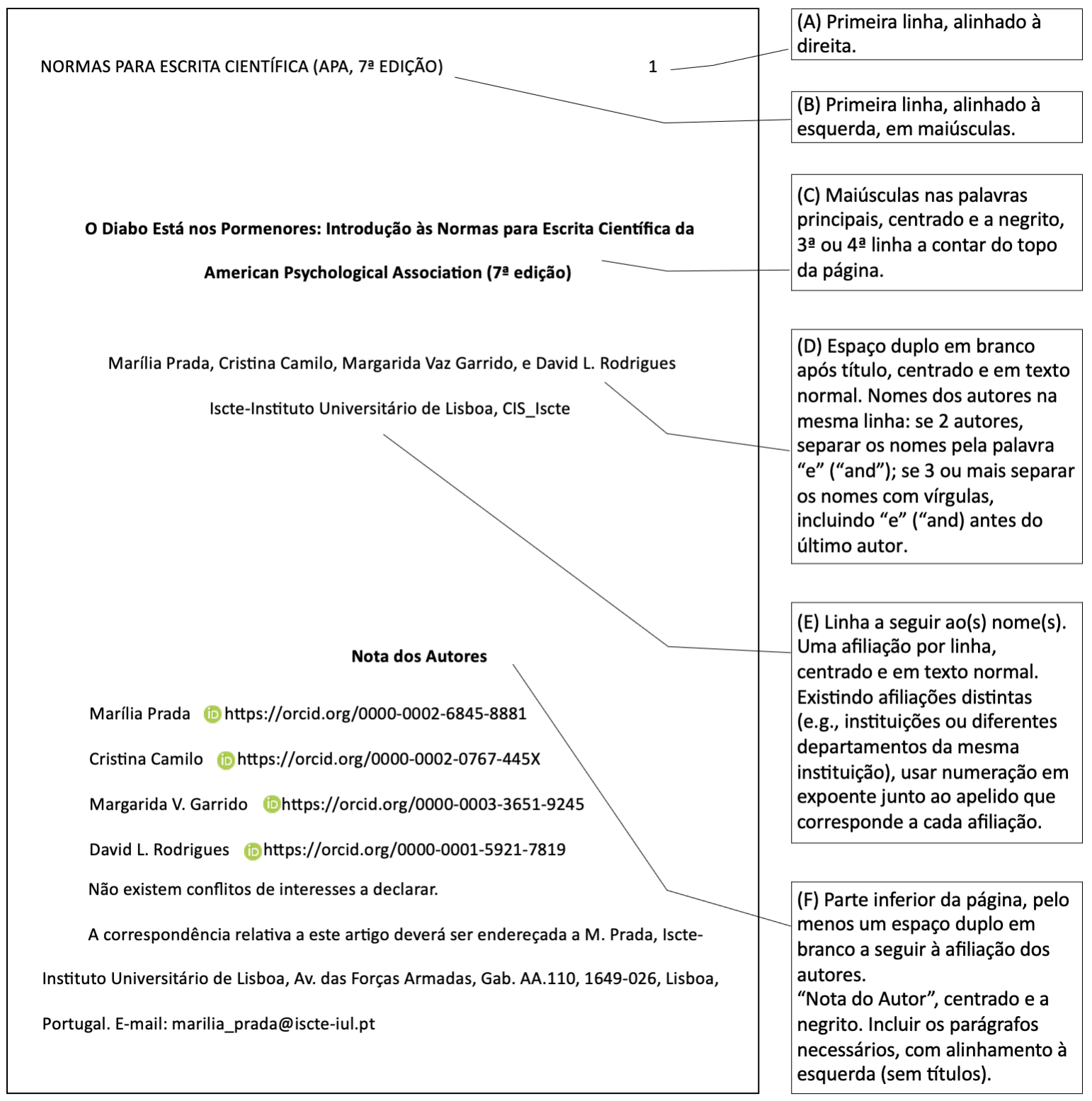

Nota. No caso de trabalhos em unidades curriculares, ainda que a APA sugira uma estrutura de base para a capa, deverá ter-se em conta as orientações do docente a respeito da capa. Na generalidade dos casos, a estrutura apresentada pode ser adaptada, incluindo elementos como: título do trabalho, nome de autor (e respetivo número de estudante), nome da instituição de ensino (incluindo departamento), identificação da unidade curricular, identificação do(s) docente(s) e data de entrega.

\section{Resumo e Palavras-Chave}

Como o próprio nome indica, o resumo (ou abstract) consiste num sumário do conteúdo do manuscrito. É apresentado na segunda página, com o título "Resumo" centrado e a negrito e, habitualmente, inclui até 250 palavras, organizadas num único parágrafo (sem avanço na primeira 
NORMAS DE ESCRITA CIENTÍFICA (APA, 7ạ EDIÇÃO)

linha). Uma alternativa, requerida por algumas revistas científicas, é o chamado resumo estruturado, que inclui subtítulos (a negrito) para indicar as diferentes secções (e.g., Objetivo, Método, Resultados, Conclusões).

Numa linha abaixo do resumo, é indicado o subtítulo "Palavras-Chave" (ou Keywords), em itálico e com avanço de parágrafo. As palavras-chave são as palavras, frases ou acrónimos que descrevem os aspetos mais relevantes do estudo, e são usadas pelas bases de dados para ajudar os leitores a encontrar o artigo em causa. Habitualmente são requeridas entre três e cinco palavras, escritas em minúsculas (exceto nomes próprios) e separadas por vírgulas. Não usar ponto final (ou outro sinal de pontuação) depois da última palavra-chave.

\section{Corpo do Texto}

O texto pode ser organizado de diferentes formas, dependendo do tipo de artigo. A generalidade dos artigos inclui uma secção introdutória que contempla a importância do trabalho, contextualizando-a à luz da literatura, e define os objetivos. Tipicamente, os trabalhos empíricos (e.g., apresentam dados originais) incluem ainda as secções de método, resultados e discussão. 0 corpo do texto inicia-se na terceira página (i.e., a seguir à página de título e à de resumo), com o título do trabalho centrado, a negrito e com maiúsculas nas palavras principais. A formatação geral do corpo do texto está sistematizada na Tabela 1.0 sistema de títulos permite destacar as diferentes seç̧ões, não sendo necessário usar quebras de página ou espaços em branco para esse efeito.

\section{Lista de Referências}

É através da lista de referências que os leitores têm acesso aos trabalhos prévios que serviram de base ao atual. Tal como os dados suportam as interpretações e conclusões, as referências servem para substanciar afirmações feitas acerca da literatura consultada. Devem ser em quantidade suficiente para suportar a necessidade do trabalho apresentado, contextualizando-o à luz da investigação anterior. Apresentaremos a organização e formatação da lista de referências em detalhe numa secção subsequente. 
NORMAS DE ESCRITA CIENTÍFICA (APA, 7ạ EDIÇÃO)

\section{Notas de Rodapé}

As notas de rodapé podem ser adicionadas a qualquer tipo de trabalho e servem para, de forma breve, indicar autoria ou copyright (e.g., no caso de uma imagem ou instrumento), ou fornecer conteúdo adicional que complementa a informação do texto. Dado que as notas de rodapé podem ser distrativas, devem ser usadas com parcimónia e apenas quando contribuem para a argumentação. Cada nota deste tipo deve veicular uma única ideia. Caso sinta a necessidade de escrever um parágrafo mais extenso, deve decidir se a informação é essencial o suficiente para integrá-la no texto. Se for acessória, poderá ser desejável eliminá-la ou remetê-la para anexo.

As notas de rodapé são identificadas por números (em sobrescrito ou superscript), na ordem em que aparecem no texto. Caso seja necessário remeter para uma nota já apresentada, deverá identificar-se a nota no texto (e.g., "ver Nota de Rodapé 5" ou "see Footnote 5"). Habitualmente, as notas de rodapé são apresentadas no final da página em que são mencionadas (tamanho de letra 10 e espaçamento simples). Uma alternativa será apresentá-las no final do texto, após as referências, com o título "Notas de Rodapé" (a maiúsculas, centrado e a negrito), seguindo-se uma nota por parágrafo a espaçamento duplo.

\section{Anexos}

Os anexos (ou apêndices) correspondem a materiais que complementam o conteúdo do manuscrito (e.g., ajudam os leitores a compreender, avaliar ou replicar o estudo ou argumento teórico apresentado), mas que seriam distrativos se incluídos no corpo do texto. Por exemplo, é adequado incluir como anexos materiais relativamente breves, como instruções dadas aos participantes, instrumentos (testes, escalas, guiões de entrevista, etc.), listas de estímulos, ou detalhes de equipamentos. A bem da transparência, muitas revistas científicas também possibilitam o acesso aberto a materiais suplementares que podem incluir as bases de dados ou outros tipos de materiais mais complexos. Por exemplo, num artigo publicado na Behavior Research Methods, Garrido et al. (2017) incluem uma hiperligação para um conjunto de materiais suplementares 
NORMAS DE ESCRITA CIENTÍFICA (APA, 7ạ EDIÇÃO)

(supplementary materials) que inclui estímulos de diferentes formatos (vídeos e fotografias de expressões faciais).

Cada anexo deverá ser apresentado numa página independente no final do manuscrito. Caso seja apenas um, o título a incluir é "Anexo". Se forem vários, cada um deve ser identificado por uma letra maiúscula segundo a ordem em que cada um é mencionado no texto (e.g., "Anexo A", "Anexo $B^{\prime \prime}$, etc.)

\section{Estilo}

O manual dedica um capítulo inteiro às questões de estilo (Capítulo 6 - "Mechanics of Style", pp. 151-191), onde são discutidas em detalhe questões relacionadas com formatação (para especificidade, ver secção relativa à estrutura do manuscrito), pontuação, ortografia, utilização de maiúsculas, hifenização, etc. À semelhança da versão anterior (para revisão, ver Prada \& Garrido, 2013), e tendo em conta as diferenças entre as línguas inglesa e portuguesa, optámos por não rever em profundidade todas as sugestões, salientando apenas as que têm maior aplicabilidade ao nosso contexto.

Uma consideração importante é a consistência. Por exemplo, no caso da ortografia é importante ser consistente na utilização (ou não) do acordo ortográfico. A Tabela 3 sistematiza em que situações deve ser usada ou evitada a apresentação de texto em maiúsculas, itálico ou negrito, e a Tabela 4 refere-se à utilização de sinais de pontuação. 
NORMAS DE ESCRITA CIENTÍFICA (APA, 7ạ EDIÇÃO)

\section{Tabela 3}

Exemplos de Utilização de Estilos de Formação

\begin{tabular}{ll}
\hline Uaiúsculas & - Palavras no início de uma frase ou a primeira palavra a seguir a dois pontos \\
& - Nomes próprios \\
& - Nomes de grupos raciais ou étnicos \\
& - Nomes de instituições académicas, departamentos e unidades curriculares \\
& - Nomes de marcas (não incluir símbolo de copyright @ em trabalhos académicos) \\
& - Doenças, síndromes, teorias, princípios, modelos, entre outros, apenas se incluem um nome \\
& próprio teoria Freudiana; síndrome de Down; doença de Lyme \\
& - Títulos de instrumentos e procedimentos Implicit Association Test; Measure of Initial Attraction \\
& - Nomes seguidos de letras ou algarismos que remetem para uma posição específica numa \\
& série Anexo C, Figura 2, Capítulo 10 \\
& - Nomes de efeitos ou variáveis apenas quando acompanhadas de sinal de multiplicação (e.g., \\
& na descrição de uma ANOVA) Interação entre Sexo x Idade x Peso \\
& NÃO USAR \\
- Quando o nome de pessoa (van der Kellen), marca/produto (iPhone) ou termo estatístico é \\
iniciado com minúscula (teste $t$ ou $p$ value). Para evitar iniciar frases com minúsculas, poderá ser \\
preferível reformular a frase. \\
- Nomes de instrumentos ou procedimentos genéricos (e.g., medida de recordação livre) \\
- Para referir uma página ou parágrafo específico \\
- Para identificar nomes de grupos ou condições num experimento \\
... aleatoriamente distribuídos pelos grupos experimentais e de controlo. \\
... condições alimentação biológica e convencional.
\end{tabular}

Itálico - Termos-chave (ou frases), frequentemente acompanhados de uma definição. Apenas deve ser utilizado uma vez, quando se pretende chamar a atenção do leitor, não necessariamente na primeira menção (e.g., se usado num título, poderá destacar-se com itálico apenas no texto quando acompanhado por uma definição). O efeito de primação semântica refere-se a...

- Nos seguintes elementos da lista de referências: títulos de livros, títulos e número de volume de publicações periódicas (ver secção Referências)

- Letras usadas como símbolos estatísticos ou matemáticos MSE, d de Cohen

- Âncoras de escalas (mas não o número associado) ....avaliado com uma escala de 7 pontos ( 1 = Nada saudável a 7 = Muito saudável)

- Primeira utilização de palavra, frase ou abreviatura estrangeira pouco familiar para os leitores.

- Sistema de títulos (nível 3 e 5)

NÃO USAR

- Título de uma série de livros (e.g., Senhor dos Anéis, Harry Potter)

- Sinal de pontuação a seguir a palavra ou frase apresentada em itálico o que é o mindfulness?

- Pontuação entre elementos de uma referência bibliográfica como o ponto a seguir ao título de um livro

- Letras gregas ou abreviaturas de elementos químicos

- Letras usadas como abreviaturas Tempo de Resposta (TR)

- Palavra de origem estrangeira incluída no dicionário da língua do trabalho (e.g., palavras de origem inglesa como internet ou website dispensam itálico num trabalho em português porque se tornaram familiares nas últimas décadas e integram dicionários de língua portuguesa.)

Negrito Título do trabalho

Sistema de títulos (nível 1 a nível 5) 
NORMAS DE ESCRITA CIENTÍFICA (APA, 7ạ EDIÇÃO)

\section{Tabela 4}

\section{Exemplos de Utilização de Pontuação}

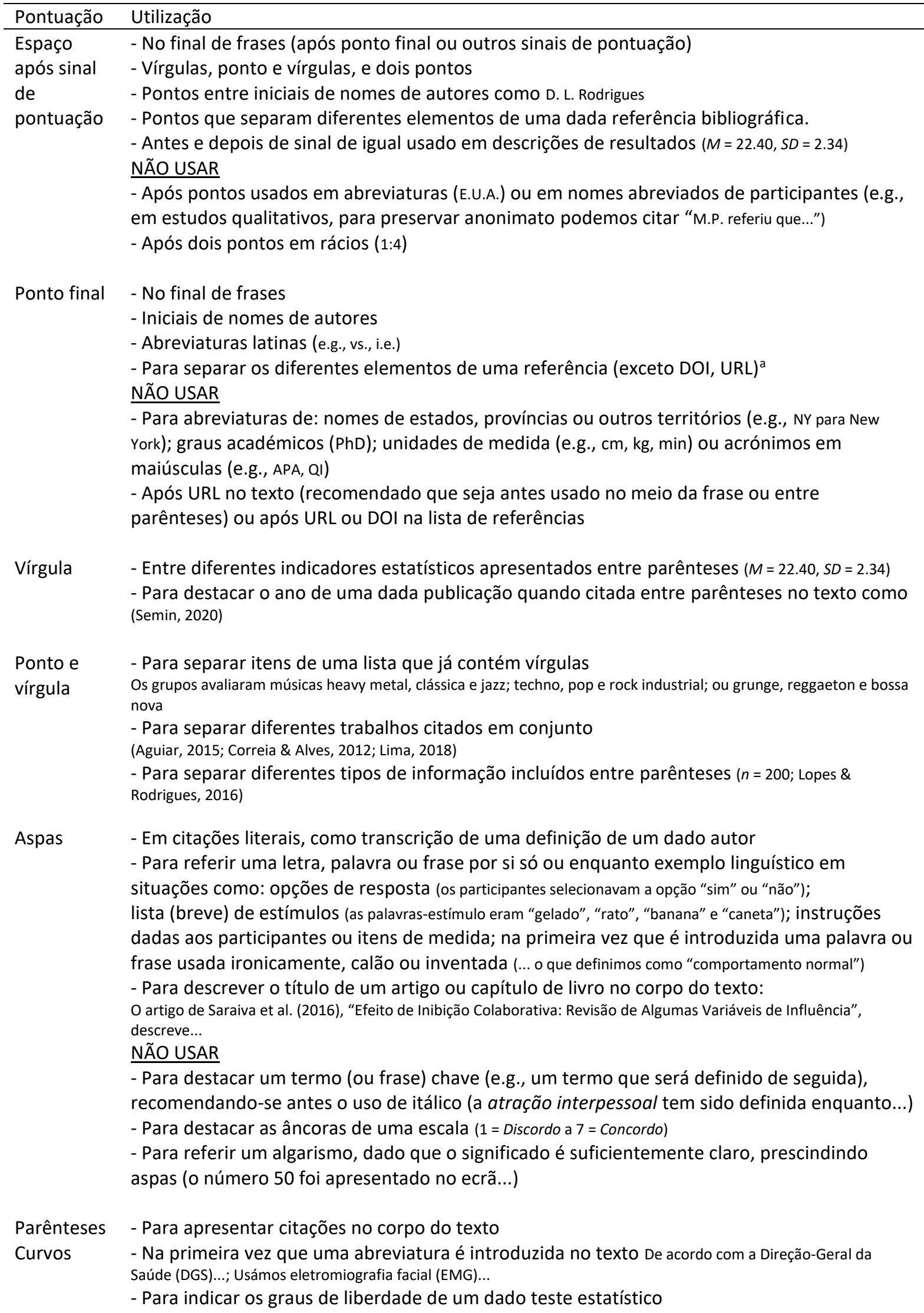


NÃO USAR

- Para destacar informação que já está apresentada entre parênteses. Em vez disso, usar parênteses retos... diferentes símbolos (Lisbon Symbol Database [LSD]; Prada et al., 2016)

- Para apresentar informação estatística que já inclui parênteses. Em vez disso, usar vírgulas: Correto: ... significativo, $t(345)=4.68, p<.001$. Incorreto: ... significativo $(t(345)=4.68, p<.001)$

- A seguir a outra informação entre parênteses. Em vez disso, usar ponto e vírgula

Correto: (e.g., primação afetiva; Prada \& Garcia-Marques, 2010) Incorreto: (e.g., primação afetiva) (Prada \& GarciaMarques, 2010)

Parênteses (ver situações em que não se aplica a utilização de parênteses curvos)

Retos

Barra - Para especificar duas possibilidades e/ou; Latino/a

- Para separar unidades de medida acompanhadas por um valor numérico $10.5 \mathrm{mg} / \mathrm{kg}$

- Para apresentar fonemas /o/

- Em citações de trabalhos traduzidos, reeditados ou republicados (ou seja, em que há duas

datas) William James (1890/2017)

NÃO USAR

- Sempre que a frase fique mais clara com a conjunção "ou" A participação no estudo foi autorizada pelos pais ou encarregados de educação das crianças.

${ }^{a}$ DOI refere-se a Digital Object Identifier e consiste numa sequência alfanumérica para identificar conteúdos e fornecer uma ligação à sua localização na Internet. Já URL refere-se a Uniform Resource Locator e consiste num endereço de rede no qual se encontra determinado recurso.

\section{Abreviaturas}

As abreviaturas podem ser muito úteis quando se referem a termos muito longos ou técnicos. Ainda assim, para não comprometer a clareza do texto devem ser usadas com parcimónia. Ainda que não seja estipulado um limite para a quantidade de abreviaturas utilizadas num manuscrito, é evidente que será mais fácil compreender o texto quando não está sobrecarregado de abreviaturas. Regra geral, as abreviaturas podem ser utilizadas quando são convencionais (e.g., VIH para Vírus da Imunodeficiência Humana) ou familiares para a audiência (e.g., QI para Quociente de Inteligência) ou quando são utilizadas pelo menos três vezes ao longo do texto. Na generalidade dos casos, na primeira vez que é utilizada, a expressão a abreviar é escrita por extenso surgindo depois a abreviatura entre parênteses (ou entre parênteses retos, caso a versão por extenso já esteja entre parênteses). Por exemplo:

... transtorno do espectro do autismo (TEA).

... (transtorno do espectro do autismo [TEA]).

Quando a abreviatura é acompanhada por uma citação, a citação deve ser separada por um ponto e vírgula.

... utilizámos a escala Regulatory Focus in Sexuality (RFS; Rodrigues et al., 2019).

... utilizámos uma escala de nove itens (Regulatory Focus in Sexuality [RFS]; Rodrigues et al., 2019). 
NORMAS DE ESCRITA CIENTÍFICA (APA, 7ạ EDIÇÃO)

No caso de tabelas e figuras, a descrição da abreviatura deve ser apresentada mesmo que já tenha surgido no texto precedente (incluindo outras tabelas ou figuras). O pressuposto é que o leitor não deverá precisar de percorrer o texto para conseguir interpretar a informação. A abreviatura pode ser apresentada por extenso na primeira vez em que é mencionada na tabela (e.g., no título) ou em nota ou legenda. Porém, quando a forma abreviada é a mais usual (como vimos no exemplo de VIH ou QI), e quando a abreviatura se refere a uma expressão latina (como "vs." ou "e.g.," para versus e por exemplo, respetivamente) ou estatística (como $M$ ou $D P$, para média e desvio-padrão, respetivamente), não é necessário escrever por extenso a que se refere.

Na generalidade, segundo a gramática Inglesa, para apresentar uma abreviatura no plural, deverá acrescentar-se um "s" em letra minúscula (e.g., Eds., ps), exceto para o plural da abreviatura de unidades de medida (e.g., 10 km e não 10 kms, 2 m e não 2 ms) e de página (pp. 10-12 e não ps. 10-12).

\section{Abreviaturas de Unidades de Medida}

Quando acompanhadas por valores numéricos, as unidades de medida poderão ser apresentadas de forma abreviada (e.g., $15 \mathrm{~min}, 30 \mathrm{~cm}, 38^{\circ} \mathrm{C}$ ), dispensando a identificação por extenso da abreviatura (para lista completa de abreviaturas de unidades de medida, ver p. 175, APA, 2020). Como ilustrado no exemplo anterior, entre algarismo e unidade de medida deverá ser inserido um espaço (exceto para ângulos, percentagens e moeda: $90^{\circ}$ e não $90^{\circ} ; 67 \%$ e não 67 \%; $75 €$ e não $75 €$ ). Em caso de não se pretender apresentar um valor numérico, deverá escrever-se o nome completo da unidade de medida (e.g., "o desperdício alimentar foi medido em gramas"). Destacamos ainda que, à exceção de percentagens e valores monetários, devemos evitar a repetição da unidade de medida quando nos referimos a valores múltiplos (e.g., "60-75 kg" ou "1, 3 ou 5 km", mas "25€-30€" e "91\%-95\%"). O mesmo se aplica à descrição de resultados estatísticos - por exemplo, deve apresentar-se a unidade de medida para o valor da média, mas não para o desviopadrão:

$\ldots(M=10.3$ anos, $D P=2.7)$ e não $\ldots(M=10.3$ anos, $D P=2.7$ anos $)$ 
NORMAS DE ESCRITA CIENTÍFICA (APA, 7ạ EDIÇÃO)

\section{Abreviaturas de Unidades de Tempo}

No caso de abreviaturas de unidades temporais podemos abreviar todas as unidades (se acompanhadas de valor numérico), tais como hora (hr), minuto (min), segundo (s) ou milissegundo (ms), à exceção de ano, mês, semana e dia, que são sempre escritos por extenso.

\section{Abreviaturas Latinas}

Os trabalhos científicos recorrem com muita frequência a abreviaturas latinas (ver Tabela 5) que, à exceção de "et al.", apenas devem ser usadas entre parênteses. No corpo do texto deve ser usada uma expressão equivalente à abreviatura na língua em que se está a redigir o texto. Por exemplo:

... no desempenho de homens versus mulheres...

... no desempenho (homens vs. mulheres) ...

\section{Tabela 5}

Expressões e Abreviaturas Latinas Mais Comuns e Correspondência em Português e Inglês

\begin{tabular}{llll}
\hline Abreviatura latina & Latim & Português & Inglês \\
\hline e.g., & Exempli gratia & Por exemplo, & For example, \\
i.e., & Id est & Isto é, & That is, \\
etc., & Et cetera & , e outras coisas & , and so forth \\
vs. & Versus & Versus / contra & Versus /against \\
cf. & Confer & Comparar & Compare \\
viz. & Videlicet & Nomeadamente, & Namely, \\
et al., & Et alii & E outros / E colaboradores & And others / And colleagues \\
\hline
\end{tabular}

\section{Números}

A regra geral é utilizar algarismos para descrever números:

- Iguais ou superiores a 10 (números de um a nove deverão ser escritos por extenso);

- Que precedem unidades de medida;

- Que representam funções matemáticas ou estatísticas, percentagens, rácios, percentis (“apenas $2 \%$ da amostra..."); 
NORMAS DE ESCRITA CIENTÍFICA (APA, 7ạ EDIÇÃO)

- Referentes a tempos específicos ("a fase de recolha de dados demorou 3 meses"), número de pontos de uma escala ("escala de 5 pontos" ou "5-points scale"), valores monetários (“...pela participação receberam um cartão-presente de $\left.10 €^{\prime \prime}\right)$.

Para além de números até nove, os números devem ser escritos por extenso sempre que correspondam a expressões universais ("doze apóstolos") ou iniciem uma frase - se possível, reformular o texto para evitar essa situação ("Trinta porcento da amostra indicou ter uma relação amorosa"). Os números ordinais obedecem à mesma regra que os cardinais (e.g., "primeiro grupo" ou "um grupo"; "12ำensaio" ou "ensaio 12"). Ainda que o sufixo seja constante em português (10으, 90 , etc.), em inglês varia consoante o número (1st, 2 nd, $3 \mathrm{rd}, 4$ th, 10 th, etc.) e pode ser apresentado em sobrescrito ou não (e.g., $1^{\text {st }}$ ou 1st), mas é importante ser consistente ao longo do trabalho. Também o separador decimal varia consoante se trate da língua portuguesa ou inglesa (usando-se vírgula ou ponto, respetivamente). Dado que a APA recomenda a separação de indicadores estatísticos com vírgula sugerimos adotar o ponto, com vista a potenciar a legibilidade. Por exemplo:

Correto: $\ldots$ avaliações mais negativas $(M=5.67, D P=1.02)$.

Incorreto: $\ldots$ avaliações mais negativas $(M=5,67, D P=1,02)$.

Salientamos ainda que a apresentação de números decimais dispensa a inclusão do valor zero desde que o valor estatístico não possa ser superior a um, nomeadamente no caso de correlações (que variam entre -1 e +1 ), valores de significância ( $p$ value assume 1 como valor máximo) ou proporções.

$$
r(560)=-.78, p=.001
$$

Caso o valor da estatística em causa possa ser superior a um (valores do teste $t$ ou $F$ numa ANOVA, desvios-padrão, etc.), devemos incluir o zero.

$$
t(230)=0.97, p=.877
$$

Na generalidade dos casos é recomendada a utilização de duas casas decimais. Já o valor exato de $p$ value observado (e.g., $p=.043$ ) pode ser apresentado com duas ou três casas decimais (sendo três o mais usual). A única exceção é para valores de $p$ inferiores a .001, que devem ser reportados como $p<.001$. 
NORMAS DE ESCRITA CIENTÍFICA (APA, 7ạ EDIÇÃO)

\section{Apresentação de Informação Estatística e Matemática}

A APA sistematiza uma série de recomendações acerca de como apresentar informação estatística ou matemática no texto, tabelas ou figuras. Para decidir qual o melhor formato deverá considerar-se a quantidade de informação numérica (e.g., médias) a apresentar:

(a) Até três: Apresentar em texto,

(b) Entre 4 e 20: Apresentar em tabela,

(c) Mais que 20: Apresentar em figura.

Porém, o mais importante será assegurar que o formato escolhido é o que otimiza a compreensão dos dados por parte do leitor, podendo mesmo ser necessário incluir informação adicional em anexo. Como as recomendações da APA têm por base os standards de conteúdo (e forma) estatística da área da Psicologia, não é necessário incluir referências para fórmulas, testes ou indicadores estatísticos comummente usados (e.g., ANOVA). Se necessário, consultar manuais de referência que incluem exemplos pedagógicos, como "Discovering Statistics Using IBM SPSS Statistics" (2017) de Andy Field, "Análise Estatística com o SPSS Statistics" (2018) de João Marôco ou os manuais disponibilizados pela R Development Core Team, na página da internet dedicada ao software R (https://cran.r-project.org/doc/manuals/r-release/R-intro.pdf). Quando se apresenta estatística inferencial (e.g., teste $t$, teste $F$, Qui-quadrado) no texto, devemos incluir informação básica (e.g., média e desvio-padrão das células), bem como o tamanho do efeito e, preferencialmente, o respetivo intervalo de confiança.

Tal como esperado, verificou-se que pessoas sem uma relação amorosa (vs. pessoas numa relação amorosa) perceberam maior ameaça à sua saúde sexual $(M=2.74, S D=1.45$ vs. $M=1.88, S D=1.20), t(398)=$ $6.48, p<.001, d=0.65$, IC 95\% [0.45, 0.85].

Um princípio-base é o de evitar a redundância, logo, se a informação descritiva é apresentada em tabela ou figura, não deverá ser repetida no texto, devendo remeter-se para a respetiva tabela ou figura.

“... o desempenho foi melhor na condição de grupo versus isolamento (ver Tabela 3)". 
NORMAS DE ESCRITA CIENTÍFICA (APA, 7ạ EDIÇÃO)

No entanto, as tabelas ou figuras apenas apresentam a informação, devendo a sua interpretação ser explicitada no texto, sendo que o autor poderá salientar dados que ajudem a interpretar o padrão de evidências. Quando se enumeram estatísticas semelhantes, é essencial que não existam dúvidas acerca dos referentes. Para tal, pode ajudar a utilização de palavras como "respetivamente":

“... verificaram-se tempos de resposta mais rápidos na avaliação de faces versus objetos $(M=610, D P$ $=120$ e $M=740, D P=133$, respetivamente), $t(299)=4.56, p<.001, d=1.22$ ".

Para referir indicadores estatísticos são usados uma variedade de abreviaturas e símbolos. A Tabela 6 sistematiza alguns dos mais comuns (para lista completa, ver APA, 2020, pp. 183-186), indicando ainda quais destas abreviaturas ou símbolos dispensam definição no texto (e.g., todos os que incluem letras gregas).

Os símbolos e abreviaturas estatísticos apenas devem ser usados entre parênteses ou quando associados a um operador matemático como o sinal de igual. Quando integrados na narrativa, devem ser usados os termos completos:

Correto: $O$ padrão de médias... /... que a condição de controlo $(M=55.4, D P=12.3)$.

Incorreto: O padrão de Ms... / ...que a condição de controlo (média = 55.4, desvio-padrão = 12.3)

A regra é semelhante para símbolos, para percentagem e para moeda (i.e., apenas usar a abreviatura/símbolo quando acompanhado de valor numérico e repetir quando se apresenta valores múltiplos): corretas..."]

Para determinar a percentagem de respostas corretas... [e não "para determinar a \% de respostas

Em geral, observou-se um elevado número de acertos (i.e., 98\% de acertos)...

Os participantes referiram estar dispostos a pagar entre $20 €$ a $30 €$ pelo produto...

As estimativas de preço foram medidas em Euros.

A nível de formatação, a generalidade dos termos estatísticos deve ser apresentada em itálico (exceto os representados por letras gregas); e deve introduzir-se um espaço antes e depois de sinais de igual e de mais e apenas espaço antes de sinal de menos (para indicação de valor negativo). 
NORMAS DE ESCRITA CIENTÍFICA (APA, 7ạ EDIÇÃO)

\section{Tabela 6}

Abreviaturas ou Símbolos para Indicadores Estatísticos

\begin{tabular}{|c|c|c|}
\hline $\begin{array}{l}\text { Abreviatura ou } \\
\text { símbolo }\end{array}$ & Definição (Português / Inglês) & $\begin{array}{l}\text { Dispensa } \\
\text { apresentação } \\
\text { por extenso? }\end{array}$ \\
\hline ACP / PCA & Análise de componentes principais / Principal components analysis & Não \\
\hline AFC / CFA & Análise fatorial confirmatória/ Confirmatory factorial analysis & Não \\
\hline AFE / EFA & Análise fatorial exploratória / Exploratory factorial analysis & Não \\
\hline ANCOVA & Análise de covariância/ Analysis of covariance & Não \\
\hline ANOVA & Análise de variância/ Analysis of variance & Não \\
\hline$d$ & $\begin{array}{l}d \text { de Cohen - medida de tamanho do efeito de comparação de duas } \\
\text { médias / Cohen's measure of sample effect size for comparing two } \\
\text { sample means }\end{array}$ & Sim \\
\hline$D P / S D$ & Desvio-padrão/ Standard deviation & Sim \\
\hline$E P / S E$ & Erro-padrão/ Standard error & Sim \\
\hline$F$ & Distribuição F; rácio de F de Fisher / F distribution; Fisher's F ratio & Sim \\
\hline$g l / d f$ & Graus de liberdade / Degrees of freedom & Sim \\
\hline $\mathrm{IC} / \mathrm{Cl}$ & Intervalo de confiança/ Confidence interval & Não \\
\hline ICA / CFI & Índice comparativo de ajustamento / Comparative fit index & Não \\
\hline LI e LS / LB and UB & $\begin{array}{l}\text { Limite inferior e superior de intervalo de confiança }{ }^{a} \text { / Lower and upper } \\
\text { bound of confidence interval }\end{array}$ & Não \\
\hline MANCOVA & Análise de covariância multivariada / Multivariate analysis of covariance & Não \\
\hline MANOVA & Análise de variância multivariada / Multivariate analysis of variance & Não \\
\hline Mdn & Mediana / Median & Sim \\
\hline MLG / GLM & Modelo linear generalizado / Generalized linear model & Não \\
\hline MLH / HLM & Modelo linear hierárquico / Hierarchical lineal model(ing) & Não \\
\hline$n$ & Número de casos (habitualmente, subamostra) & Sim \\
\hline$N$ & Número total de casos & Sim \\
\hline$r$ & Coeficiente da correlação de Pearson / Pearson's correlation coeficient & Sim \\
\hline$R$ & Correlação múltipla / Multiple correlation & Sim \\
\hline$t$ & $\begin{array}{l}\text { Distribuição } t \text { de Student; teste estatístico baseado na distribuição } t \text { de } \\
\text { Student / Student's } t \text { test }\end{array}$ & Sim \\
\hline$\alpha$ (alfa) & $\begin{array}{l}\text { Alfa de Cronbach (medida de fidelidade: consistência interna) / } \\
\text { Cronbach's alpha }\end{array}$ & Sim \\
\hline$\beta$ (Beta) & $\begin{array}{l}\text { Coeficiente de regressão estandardizado / Standardized regression } \\
\text { coeficient }\end{array}$ & Sim \\
\hline$b$ (beta) & $\begin{array}{l}\text { Coeficiente de regressão não-estandardizado / Unstandardized } \\
\text { regression coeficient }\end{array}$ & Sim \\
\hline$\eta^{2}$ (eta quadrado) & $\begin{array}{l}\text { Medida de força da relação ou tamanho do efeito / Measure of strength } \\
\text { of association or effect size }\end{array}$ & Sim \\
\hline$\chi^{2}$ (qui-quadrado) & $\begin{array}{l}\text { Distribuição qui-quadrado; teste estatístico baseado na distribuição qui- } \\
\text { quadrado / Chi-square distribution; statistical test based on the chi- } \\
\text { square distribution }\end{array}$ & Sim \\
\hline
\end{tabular}

Listas

A seriação deve ser utilizada para ajudar os leitores a compreender uma série de pontos interrelacionados. No âmbito de uma frase com três ou mais pontos, para separar cada ponto, 
NORMAS DE ESCRITA CIENTÍFICA (APA, 7ạ EDIÇÃO)

deverá utilizar-se uma vírgula ou, caso cada ponto já contenha vírgulas, um ponto e vírgula. Para identificar cada elemento, podemos utilizar três tipos de listas (ver Tabela 7).

\section{Tabela 7}

Tipos de Listas

\begin{tabular}{|c|c|c|}
\hline Tipo de lista & Utilização & Exemplo \\
\hline Letras & Itens mais curtos & $\begin{array}{l}\text {... três tipos de estímulos: (a) negativos, os que } \\
\text { obtiveram avaliações inferiores a } 3 \text { pontos; (b) } \\
\text { neutros, os que obtiveram avaliações superiores } \\
\text { a } 3 \text { mas inferiores a } 6 \text { pontos; e (c) positivos, os } \\
\text { que obtiveram avaliações superiores a } 6 \text { pontos. }\end{array}$ \\
\hline Números & $\begin{array}{l}\text { Para apresentar uma série de frases ou } \\
\text { parágrafos completos, habitualmente } \\
\text { ordenáveis (cronologia, importância } \\
\text { ou prioridade). }\end{array}$ & $\begin{array}{l}\text { 1. Fase de treino: Os participantes } \\
\text { realizavam uma série de } 10 \text { ensaios... } \\
\text { 2. Tarefa principal: Esta tarefa consistiu } \\
\text { em... } \\
\text { 3. Questões de controlo: Por último, os } \\
\text { participantes responderam a... }\end{array}$ \\
\hline $\begin{array}{l}\text { Marcador } \\
\text { tipográfico } \\
\text { (bullet points) }\end{array}$ & $\begin{array}{l}\text { Semelhante às listas numeradas, mas } \\
\text { quando não se quer sugerir que existe } \\
\text { uma ordem entre os elementos. } \\
\text { Os marcadores podem ser pequenos } \\
\text { quadrados, círculos, etc. }\end{array}$ & $\begin{array}{l}\text { Os critérios para seleção dos estímulos foram... } \\
\text { - } \quad \text { Imagens a cores; } \\
\text { - } \quad \text { Apenas um objeto representado na } \\
\text { imagem; } \\
\text { - } \quad . .\end{array}$ \\
\hline
\end{tabular}

\section{Sistema de Títulos}

A organização de um manuscrito é facilitada pela introdução de títulos e subtítulos que identificam de forma sucinta o tópico ou conteúdo de cada secção. Para facilitar a sua deteção, todos os títulos são formatados de modo a que se distingam do corpo do texto (e.g., todos são apresentados a negrito/bold). Especificamente, o estilo APA define até cinco níveis de título, em ordem decrescente de importância, sendo que o leitor deve inferir que todos os títulos do mesmo nível têm igual importância. Por exemplo, secções principais como Método, Resultados e Discussão são identificados através de um título de nível 1. Apenas a seç̧ão de Introdução dispensa título dado que é imediatamente identificável pela sua posição no manuscrito (i.e., logo a seguir ao Resumo), devendo ser iniciada pelo título do trabalho (nível 1). Em vez de ordenar os títulos com base na associação a letras ou números (e.g., "2. Método", "2.1. Participantes e Delineamento"), a identificação do nível é feita através da sua formatação específica, como a utilização de itálico e alinhamento do texto (e.g., centrado, à esquerda, com ou sem avanço). O número de níveis de título 
NORMAS DE ESCRITA CIENTÍFICA (APA, 7ạ EDIÇÃO)

a utilizar varia entre manuscritos - sendo comum utilizar até títulos de nível 3 (e.g., "Método" - nível

1; "Instrumentos" - nível 2; "Escala de Personalidade" - nível 3; "Escala de Atitudes" - nível 3).

Destacamos que apenas se deve recorrer a subtítulos se, dentro de uma mesma secção, incluirmos pelo menos duas subsecções. A Tabela 8 sistematiza estes aspetos de formatação. A Figura 2 ilustra a estrutura de um manuscrito que inclui os cinco níveis de título, especificando a formatação relativa a cada nível.

\section{Tabela 8}

Formatação dos Níveis de Título

\begin{tabular}{|c|c|c|c|c|c|}
\hline & \multicolumn{5}{|c|}{ Nível } \\
\hline & 1 & 2 & 3 & 4 & 5 \\
\hline Capitalização de título/ title case ${ }^{a}$ & $\mathrm{x}$ & $\mathrm{x}$ & $\mathrm{x}$ & $\mathrm{x}$ & $\mathrm{x}$ \\
\hline \multicolumn{6}{|l|}{ Texto em... } \\
\hline Negrito/bold & $\mathrm{x}$ & $\mathrm{x}$ & $\mathrm{x}$ & $\mathrm{x}$ & $\mathrm{x}$ \\
\hline Itálico & & & $\mathrm{x}$ & & $\mathrm{x}$ \\
\hline \multicolumn{6}{|l|}{ Alinhamento do título: } \\
\hline Centrado & $\mathrm{x}$ & & & & \\
\hline Alinhado à esquerda & & $\mathrm{x}$ & $\mathrm{x}$ & & \\
\hline Alinhado à esquerda (com avanço de 1.27 cm) & & & & $\mathrm{X}$ & $\mathrm{x}$ \\
\hline \multicolumn{6}{|l|}{ Continuação do Texto: } \\
\hline Linha abaixo ao título, avanço de $1.27 \mathrm{~cm}$ (i.e., novo parágrafo) & $\mathrm{x}$ & $\mathrm{x}$ & $\mathrm{x}$ & & \\
\hline Mesma linha do título (título termina com ponto final) & & & & $\mathrm{x}$ & $\mathrm{x}$ \\
\hline
\end{tabular}

${ }^{a}$ Por title case entende-se que todas as palavras são apresentadas em maiúsculas (exceto preposições como "a", "de" e artigos definidos como "a/o(s)" e respetivas contrações como "do/a" ou pelo/a"). 
NORMAS DE ESCRITA CIENTÍFICA (APA, 7ạ EDIÇÃO)

\section{Figura 2}

Ilustração da Formatação Relativa aos Níveis de Título

Impacto da Exposição a Estímulos Auditivos na Avaliação de Imagens

Texto inicia-se aqui como novo parágrafo (i.e., avanço de $1.27 \mathrm{~cm}$ ). 0 corpo do texto

apresenta-se alinhado à esquerda, com espaçamento duplo.

Processamento de Informação em Diferentes Modalidades

Texto inicia-se aqui como novo parágrafo.

Efeitos de Primação com Estímulos Auditivos

Texto inicia-se aqui como novo parágrafo.

\section{Método Nível 1}

\section{Participantes e Delineamento Nível 2}

Texto inicia-se aqui como novo parágrafo.

\section{Material \\ Nível 2}

\section{Estímulos visuais}

Texto inicia-se aqui como novo parágrafo.

\section{Estímulos auditivos}

Texto inicia-se aqui como novo parágrafo.

\section{Procedimento Nível 2}

Texto inicia-se aqui como novo parágrafo.

\section{Resultados Nível 1}

\section{Tarefa de Primação Nível 2}

\begin{tabular}{l|l|l} 
Julgamentos & Nível 3 & $\begin{array}{l}\text { Negrito } \\
\text { Alinhado à esquerda com avanço } \\
\text { Capitalização de título }\end{array}$
\end{tabular}

Dimensões Avaliativas. $\quad$ Nível 4 Termina com ponto

Valência. Texto inicia-se na mesma linha.

Familiaridade. Texto inicia-se na mesma linha.

Tempos de Resposta Nível 2

\section{Nível 5}

Negrito / Itálico

Alinhado à esquerda

Capitalização de título

Termina com ponto

Negrito / Itálico

Alinhado à esquerda

Capitalização de título

\section{Nível 1 [Título manuscrito]}

Negrito

Centrado

Capitalização de título
Nível 2 [Subtítulos da introdução]

Alinhado à esquerda

Capitalização de título

$(\ldots)$

Discussão

Nivel 1 
NORMAS DE ESCRITA CIENTÍFICA (APA, 7ạ EDIÇÃO)

\section{Tabelas e Figuras}

A utilização de tabelas e figuras permite apresentar, de modo eficiente, uma grande quantidade de informação. As tabelas habitualmente apresentam valores numéricos (e.g., médias e desvios-padrão) ou informação textual (e.g., listas de estímulos) ordenados em linhas e colunas. Já as figuras incluem todas as outras formas de representação gráfica (e.g., esquemas, fotografias, gráficos, ilustrações). Enquanto as tabelas podem ser desenvolvidas diretamente no processador de texto (ou adaptados para o estilo APA quando importadas de programas como o Excel ou o SPSS), as figuras podem ser criadas numa variedade de programas (e.g., Powerpoint, Illustrator, Photoshop) desde que se garanta que o ficheiro final tenha uma resolução adequada. Para decidir acerca da necessidade de incluir uma tabela ou figura, deverá pensar-se se facilitará a compreensão por parte do leitor (e.g., síntese de informação extensa ou complexa) e se acrescenta algo face ao texto, não podendo ser meramente decorativas. Por exemplo, para evitar redundância, se a tabela sistematiza as médias observadas nas células experimentais, esses valores não deverão ser repetidos no texto que acompanha a tabela. Tabelas e figuras devem ser utilizados com parcimónia, caso contrário, poderão ser distrativas.

Para potenciar a clareza da comunicação devemos:

- Garantir que todas as tabelas e figuras - mesmo as apresentadas em anexo - são autoexplicativas (i.e., não requerem a leitura do texto para serem percetíveis).

- Identificar todos os elementos (e.g., colunas numa tabela; eixos de um gráfico; legenda de um gráfico; abreviaturas - mesmo se a definição já foi apresentada no texto).

- Usar letras não serifadas (e.g., Arial, Calibri, Lucida Sans Unicode) e com tamanho suficiente para leitura sem necessidade de aumento (i.e., entre 8 e 14 pontos) em imagens.

As tabelas e figuras incluem sempre uma identificação numérica, de acordo com a ordem em que são mencionadas no texto (e.g., Figura 1). Note que, por questões de paginação, nem sempre a tabela ou figura surge junto ao texto que o/a referencia (podendo mesmo ser apresentadas no final do manuscrito ou em ficheiros independentes). Por essa razão, é 
NORMAS DE ESCRITA CIENTÍFICA (APA, 7ạ EDIÇÃO)

desaconselhada a utilização de expressões como na tabela/figura "anterior" ou "acima" ou "da página $x^{\prime \prime}$.

... (para representação da interação entre língua e tipo de palavra, ver Figura 4).

Os resultados são sumariados na Tabela 2.

Como ilustrado na Tabela 5, os participantes foram mais rápidos a avaliar...

Destacamos que, caso a tabela ou figura (e.g., uma imagem de domínio público obtida na internet) constitua uma reprodução ou adaptação de outras fontes, incluindo de um trabalho prévio do próprio autor, é necessário atribuir a autoria (copyright), tanto numa nota como na lista de referências. Em alguns casos, pode ser necessário obter autorização dos autores para utilizar o material.

\section{Componentes e Formatação de Tabelas}

As tabelas incluem, obrigatoriamente, os seguintes elementos (ver Figura 3 para ilustração e formatação de cada elemento):

1. Identificação numérica: O número (e.g., Tabela 4) é definido pela ordem em que a tabela é mencionada no texto;

2. Título: $\mathrm{O}$ título deve ser conciso, mas explicativo de forma a permitir inferir o conteúdo da tabela. Abreviaturas que surjam nos cabeçalhos ou corpo da tabela podem ser definidas no título, entre parênteses.

3. Cabeçalhos das colunas: Cada coluna deve estar identificada (título das colunas centrado). A primeira coluna (i.e., a da esquerda) habitualmente refere-se à principal variável independente ou preditora que deve ser descrita de forma breve. Apenas se usam números no caso de identificar variáveis em matrizes de correlações ou quando já são referidas por números no texto. Imaginando que existem vários níveis da mesma variável (e.g., "idade" que depois se decompõe em diferentes grupos etários), os níveis podem ser destacados usando um avanço de cerca de $0.4 \mathrm{~cm}$. Um cabeçalho de coluna pode referir-se a apenas uma coluna ou a mais do que uma (e.g., usar a função "merge cells"). Toda a informação contida nas células de uma mesma coluna deve ser do mesmo 
NORMAS DE ESCRITA CIENTÍFICA (APA, 7ạ EDIÇÃO)

tipo (e.g., se o cabeçalho indica \%, todos os números deverão consistir em percentagens, dispensando o símbolo dado que já consta do cabeçalho).

4. Corpo: O corpo é constituído por todas as colunas e linhas, sendo as células o ponto de intersecção entre uma dada linha e coluna. As células podem conter informação textual, valores numéricos ou uma combinação de ambos, centrando o texto. No caso de valores numéricos, deverá utilizar-se o número de casas decimais ajustado à precisão da medida em causa (e.g., a apresentação de tempos de resposta em milissegundos poderá dispensar casas decimais, já médias verificadas em escalas de resposta podem ser apresentadas com uma ou duas casas decimais). Se possível, deverão apresentar-se todos os valores comparáveis com o mesmo número de casas decimais. Existem ainda casos em que uma ou mais células não podem ser preenchidas. Se for por os dados não se aplicarem, a célula deve ser deixada em branco; se for porque os dados não foram obtidos (e.g., falha na gravação), deve introduzir-se um travessão e explicar em nota o seu significado. Por último, os travessões apresentados em matrizes de correlações indicam necessariamente a correlação de um item consigo mesmo (i.e., 1), dispensando explicações. O corpo pode ser apresentado a espaçamento duplo, espaço e meio ou espaço simples, consoante o que facilitar a apresentação (e.g., em espaço simples poderá permitir encaixar uma tabela extensa numa única página).

5. Notas: Se necessário, cada tabela pode conter três tipos de notas apresentadas abaixo da tabela, um tipo de nota por linha, na seguinte ordem: notas gerais, específicas e de probabilidades (ver Figura 3). Múltiplas notas específicas (ou de probabilidades) devem ser apresentadas na mesma linha, separadas por uma vírgula seguida de um espaço. Caso as notas específicas sejam extensas podem ser apresentadas em linhas diferentes para promover a legibilidade. As notas devem ser apresentadas a espaço duplo e alinhadas à esquerda (sem avanço).

As notas gerais são identificadas pela expressão "Nota." (em itálico e com ponto final) e visam qualificar, explicar ou fornecer informação acerca do título ou da tabela como um todo (e.g., definição de abreviaturas, símbolos, atribuição de copyright). Já as notas específicas referem-se apenas a uma coluna, linha ou célula específica e são identificadas por letras em sobrescrito ou 
superscript $\left({ }^{a},{ }^{b}, c\right.$, etc.), em ordem alfabética da esquerda para a direita e/ou de cima para baixo. A nota correspondente apresentada por baixo da tabela é apresentada com a mesma letra. Para potenciar a legibilidade, deve ser introduzido um espaço, em sobrescrito, antes e depois da letra. As notas podem ser usadas para evitar redundâncias. Imagine-se uma tabela que descreve resultados de três condições experimentais com amostras iguais $(n=30)$. Em vez de incluir uma coluna para descrever o número de participantes de cada grupo, basta colocar uma nota específica como "Condição ${ }^{a}$ " que depois remete para a nota "a $\mathrm{n}=30$ para cada condição". Por último, as notas de probabilidade descrevem a utilização de asteriscos (ou outros símbolos) usados numa tabela para indicar o nível de significância de testes estatísticos. A recomendação é a de apresentar os $p$ values exatos obtidos, habitualmente com três casas decimais ou, se inferior a .001, poderá indicar-se $p<$ .001. Uma alternativa, exclusivamente no caso de tabelas e figuras, é usar a notação " $p<$ ", ou seja, ${ }^{*} p<.050,{ }^{* *} p<.010 \mathrm{e}^{* * *} p<.001$ (ver Figura 3).

\section{Figura 3}

Exemplo de Tabela Formatada de Acordo com o Estilo APA

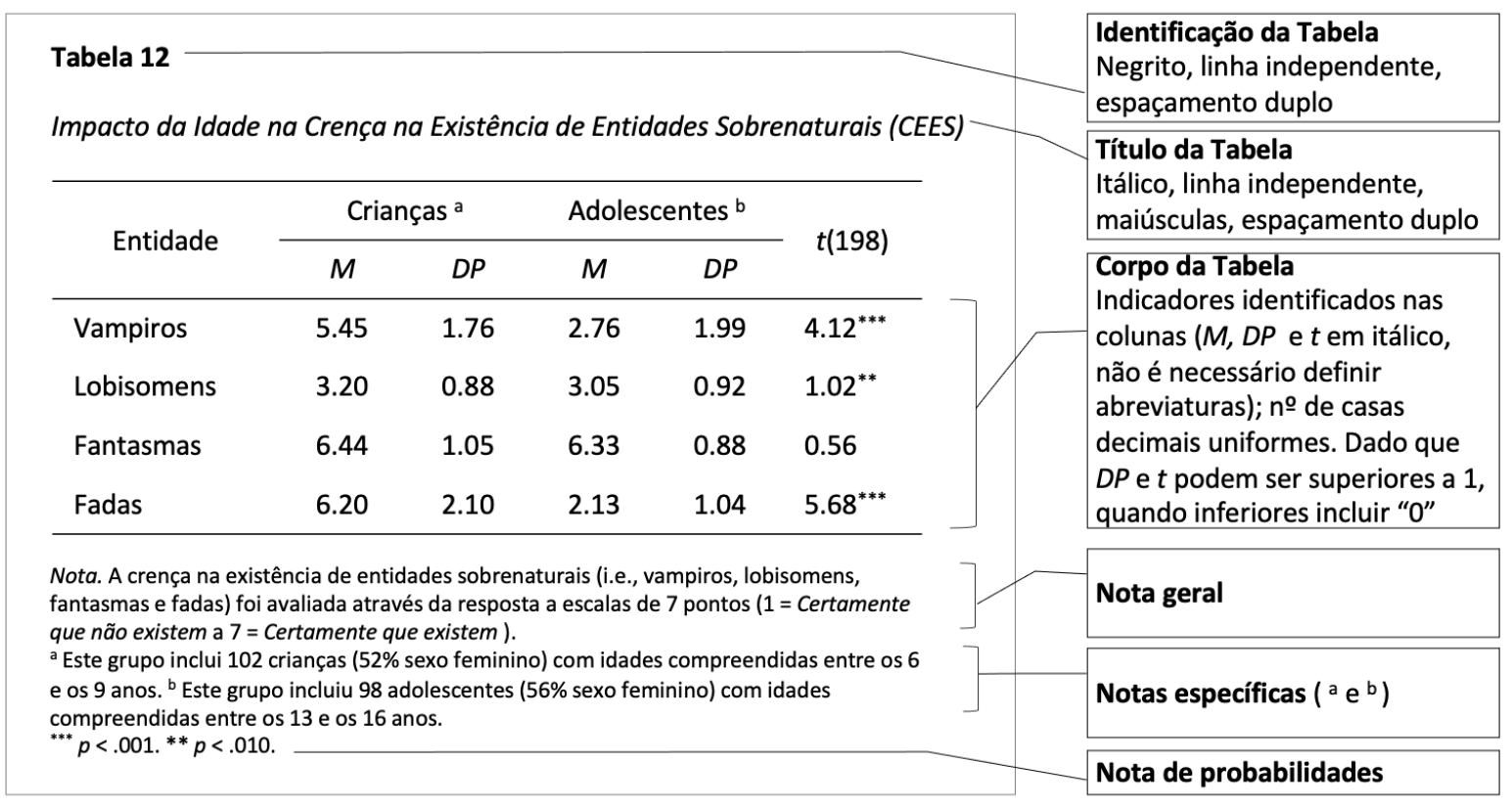

A nível de formatação, as tabelas apenas incluem as linhas horizontais necessárias para definir os limites (habitualmente, topo e base da tabela, cabeçalhos de colunas). Se necessário, pode 
NORMAS DE ESCRITA CIENTÍFICA (APA, 7ạ EDIÇÃO)

também ser introduzida uma linha horizontal para destacar uma linha que sumaria informação (e.g., total). Não devem ser utilizadas linhas verticais em nenhum caso (e.g., se quiser destacar uma dada coluna, poderá fazê-lo através de espaçamento ou linha/coluna em branco). $O$ uso de sombreados também é desaconselhado (e.g., para destacar uma célula deverá antes utilizar uma nota específica). Caso a tabela seja muito longa (i.e., mais extensa do que uma página), deverá repetir o cabeçalho, sendo preferível usar a função do processador de texto (repetição de linhas de cabeçalho ou repeat headers) do que rescrevê-lo. Caso seja demasiado larga, poderá apresentar a tabela em orientação horizontal (landscape). Por último, se for demasiado larga e longa para uma única página, deverá equacionar dividir a informação em mais do que uma tabela.

O manual da APA (2020, pp. 200, 210-224) inclui 24 exemplos de tabelas que descrevem diferentes tipos de informação (e.g., características sociodemográficas dos participantes; resultados descritivos das principais medidas; correlações; tabelas-síntese de estudos qualitativos, etc.), demonstrando assim como a estrutura-base é adaptável aos conteúdos representados.

\section{Componentes e Formatação de Figuras}

Uma boa figura acrescenta informação ao texto (i.e., não é redundante), deve ser legível (e.g., tamanho e tipo de letra adequado, boa resolução) e fácil de interpretar (i.e., o seu propósito é evidente, todos os elementos - como eixos de um gráfico - estão bem identificados, etc.) e é consistente a nível de estilo e formatação (e.g., tamanho) com outras figuras semelhantes do mesmo trabalho.

Tal como as tabelas, as figuras incluem uma série de elementos:

1. Identificação numérica: Idêntica à das tabelas (i.e., numeração pela ordem em que é mencionada no texto, apresentação acima da figura, alinhamento à esquerda e a negrito).

2. Título: $O$ título deve ser surgir na linha abaixo da identificação numérica, a espaçamento duplo, em itálico e com o título capitalizado (title case).

3. Imagem (i.e., gráfico, ilustração, fotografia, esquema, etc.). 
NORMAS DE ESCRITA CIENTÍFICA (APA, 7ạ EDIÇÃO)

4. Legenda: A legenda não é obrigatória e só deve ser apresentada para explicar informação contida na imagem (e.g., explicação do significado das cores ou padrões das barras de um gráfico).

5. Nota: Se necessário, à semelhança das tabelas, as figuras podem conter três tipos de notas (gerais, específicas ou de probabilidades). Especificamente para figuras, as notas gerais incluem a designação de abreviaturas, unidades de medidas ou símbolos não incluídos na legenda; a identificação do significado de cores ou padrões utilizados; no caso de figuras com múltiplos painéis, a descrição de cada um; caso sejam apresentadas barras de erro em gráficos, deve ser explícito a que se referem (i.e., desvios-padrão, erros-padrão, etc.); reconhecimento da fonte a partir da qual se adaptou ou reproduziu a imagem. No caso de fotografias de outro autor, é importante explicar que tipo de edição foi efetuada (para além de redimensionamento ou ajuste de luminosidade). Se a fotografia representar uma (ou mais) pessoas passíveis de identificação (e.g., rosto claramente visível) é necessário obter uma autorização escrita para a utilização da imagem (e.g., um artigo que apresenta uma nova base de fotografias de expressões faciais requer obrigatoriamente que os modelos consintam a divulgação das imagens para esse fim).

É comum, em particular no caso da publicação de artigos científicos, a impressão de trabalhos a preto e branco. Por essa razão, recomenda-se a utilização de tons que sejam facilmente distinguíveis. Por exemplo, num gráfico de barras usar contorno preto nas barras e preenchimento a branco para uma condição e a preto na outra. Caso haja mais condições, é recomendável usar padrões (e.g., riscas horizontais). Algumas publicações oferecem a possibilidade de apresentar figuras a cores na versão online e em escala cinza na versão impressa, ou a cores em ambas versões (implicando, ou não, custos de impressão para o autor). Independentemente dessas questões, a cor só deve usada se imprescindível para a compreensão da figura (e.g., dados obtidos com técnicas de imagiologia como ressonância magnética funcional), garantindo que a imagem tem o contraste necessário para ser compreensível mesmo para pessoas com algum tipo de dificuldade visual no processamento da cor (e.g., pessoas com daltonismo). Elementos meramente decorativos (e.g., efeitos 3-D em gráficos de barras) devem ser evitados. Uma figura pode conter vários painéis (e.g., 
NORMAS DE ESCRITA CIENTÍFICA (APA, 7ạ EDIÇÃO)

apresentação de dois gráficos para potenciar a comparação entre duas condições). Nesse caso, cada painel poderá ser identificado com uma letra maiúscula posicionada no quadrante superior esquerdo de cada painel, o que facilita a referência a uma secção específica da figura:

Como ilustrado na Figura 3A...

...ver Painel A da Figura 5.

O manual inclui ainda recomendações para figuras que representem dados específicos (e.g., eletrofisiológicos ou genéticos) e fornece 21 exemplos de vários tipos de figuras (APA, 2020, pp. 230250).

\section{Reconhecimento de Fontes}

Nesta secção descrevem-se os elementos contidos nos tipos de materiais bibliográficos mais frequentemente consultados por estudantes e investigadores.

Quer a redação de artigos científicos, quer de livros, capítulos ou trabalhos académicos deve privilegiar a referência a fontes credíveis, nomeadamente aquelas que implicam revisão por pares (vs. artigos de opinião). Além disso, e não obstante a importância de determinados autores, ou teorias, considerados mais clássicos, o conhecimento científico evolui rapidamente e esta evolução deve ser visível no texto através da inclusão de fontes recentes (e.g., artigos vs. handbooks que podem ser mais antigos). Quer as revistas com revisão por pares, quer a recência da publicação permitem maximizar não apenas a qualidade e atualidade dos conteúdos que estão a ser apresentados, como minimizar a utilização de termos ou conceitos que atualmente se consideram inapropriados (e.g., referência a pessoas "normais" em vez de "pessoas com desenvolvimento típico", referência a "deficientes" em vez de "pessoas portadoras de deficiência" ou até mesmo a "sujeitos" em vez de "participantes").

A apresentação de citações ao longo do texto é um fator central da escrita científica e académica. Para quem escreve é importante que as afirmações feitas encontrem fundamento na literatura. Não é necessário que as referências citadas num artigo sejam exaustivas. No entanto, estas devem ser suficientes para apoiar as ideias apresentadas e o trabalho empírico desenvolvido. As referências usadas em determinado texto científico servem a dupla função de reconhecer o que 
NORMAS DE ESCRITA CIENTÍFICA (APA, 7ạ EDIÇÃO)

foi feito anteriormente (e assim evitar o plágio), ao mesmo tempo que permitem a afirmação do contributo único do trabalho apresentado.

O processo de citação consiste em apresentar um conjunto de referências que permite identificar a origem das ideias, teorias ou resultados empíricos incluídos na construção do texto. Devem ser citadas todas as fontes que foram efetivamente consultadas e incorporadas no texto, que devem também integrar a lista de referências. As normas apresentadas no manual da APA (2020) em relação a este tema são relativamente extensas e detalhadas. Sendo necessário fazer uma seleção, iremos apresentar algumas das regras mais comummente usadas.

\section{Normas para Citações no Texto}

A regra geral indica que as fontes de informação citadas ao longo do texto devem ser identificadas com o apelido do(s) autor(es) e o ano da publicação, separados por uma vírgula. Para além disso, todas as citações apresentadas devem corresponder a uma entrada na seç̧ão de referências. Desta forma, é possível ao leitor localizar uma referência detalhada do que está a ler, fazendo a equivalência entre a citação do texto e as referências finais ordenadas alfabeticamente.

Uma das formas mais comuns de apresentar as ideias de um autor é parafrasear, ou seja, apresentar as ideias de uma terceira pessoa através das nossas próprias palavras. Quando parafraseamos podemos selecionar, sintetizar e integrar a informação recolhida, de maneira a que esta se incorpore na nossa narrativa. Esta é, portanto, uma forma estratégica de apresentar as ideias de terceiros e, segundo a APA, preferível ao uso recorrente de transcrições diretas. No entanto, apesar de as palavras serem nossas, as ideias não o são. Por isso, é sempre necessário apresentar a citação devida.

As citações no corpo de texto podem ser integradas na narrativa ou apresentadas entre parênteses. Na apresentação entre parênteses, ambos os elementos da referência, o(s) apelido(s) do(s) autor(es) e a data surgem entre parênteses:

As emoções são experienciadas como uma ativação fisiológica à qual se atribui uma designação cognitiva, que pode ser "incorreta" (Schachter, 1964). 
NORMAS DE ESCRITA CIENTÍFICA (APA, 7ạ EDIÇÃO)

Outra forma de apresentar a citação é integrá-la na narrativa, em que apenas a data é apresentada entre parênteses:

De acordo com as investigações de Schachter (1964), as emoções são experienciadas como uma ativação fisiológica à qual se atribui uma designação cognitiva, que pode ser "incorreta".

Salientamos uma diferença importante no caso de trabalhos com dois autores: se o trabalho é integrado na narrativa utiliza-se a conjunção "e" (ou "and", se o texto é redigido em inglês) para ligar os autores - Camilo e Rodrigues (2019); se é citado entre parênteses a conjunção é substituída pelo símbolo "e comercial" (e.g., Camilo \& Rodrigues, 2019). Em ambos os tipos de citação devemos observar as seguintes variações: em referências com um ou dois autores, o(s) apelido(s) dos autores surgem todas as vezes que o trabalho é citado, seguido(s) de uma vírgula e da data da publicação; em referências com três ou mais autores, só se coloca o apelido do primeiro autor, seguido da menção "et al.", de uma vírgula e da data da publicação. Esta regra aplica-se desde a primeira vez que a citação surge no texto. É possível apresentar o número da página nas paráfrases, apesar de não ser comum ou obrigatório.

As citações podem aparecer no início, no meio da frase, após ter sido apresentado o texto a que a citação se refere, ou no final da mesma. A mesma citação pode surgir tantas vezes quantas forem necessárias. No entanto, se a sequência do texto der a entender que nos estamos a referir à mesma fonte, não é necessário repetir a citação, a menos que a paráfrase se prolongue por mais do que um parágrafo. Nesse caso, a referência deverá ser repetida.

Em alguns casos, o mesmo excerto de texto pode ser sustentado por diferentes fontes. Nesse caso, podemos ter de apresentar várias citações, que devem ser integradas no mesmo parênteses e ordenadas alfabeticamente (e não por ordem cronológica, o que constitui um erro comum):

Além disso, tendem a preferir parceiros mais velhos, com bens materiais e com um status social mais elevado (Antill, 1983; Berscheid \& Walster, 1974; Byrne, et al., 1966; Chapdelaine, et al., 1999; Feingold, 1990; Graziano, et al., 1993; Jellison \& Mills, 1967; Sprecher, et al., 1994).

Caso se apresentem várias citações do(s) mesmo(s) autores, estas deverão ser ordenadas de forma cronológica (e.g., Uchino, 2004, 2009). Se tivermos citações iguais, ou seja, com os mesmos 
NORMAS DE ESCRITA CIENTÍFICA (APA, 7ạ EDIÇÃO)

apelidos e datas, mas que correspondam a referências diferentes, devemos acrescentar uma letra como sufixo (e.g., APA, 2010a, 2010b). Esta mesma letra é acrescentada à referência correspondente, de maneira a que seja possível estabelecer a equivalência entre citação e referência. Caso dois autores partilhem o mesmo apelido, as citações devem incluir as iniciais dos primeiros nomes (mesmo que as datas sejam diferentes) para que seja possível distingui-los (e.g., D. Rodrigues, 2009; M. Rodrigues, 2015)

As citações narrativas apresentam algumas particularidades em relação às citações que surgem entre parênteses. Por exemplo, quando são apresentadas diversas citações narrativas associadas a um trecho de texto, estas não seguem uma ordem particular (nem alfabética, nem cronológica). Outra diferença diz respeito à apresentação da data da citação: nas citações narrativas a data apenas surge na primeira vez que a referência é apresentada, não havendo necessidade de a repetir em citações subsequentes. No entanto, se a mesma citação surgir mais tarde entre parênteses, a data deve voltar a ser incluída.

As fontes de informação são classificadas como primárias (i.e., quando consultamos o documento onde originalmente surge a informação citada) ou como secundárias (i.e., quando temos acesso à informação em segunda mão, ou seja, através de um autor que relata o que um terceiro autor escreveu). Apenas devemos recorrer a fontes secundárias quando a fonte primária não está acessível (e.g., quando o trabalho já não é editado ou quando não se encontra publicado numa língua acessível ao leitor). Neste caso, ambas as fontes devem ser citadas no texto, mas apenas a fonte secundária surge na lista de referências. Imagine que lê o trabalho de Rodrigues (2020), onde este cita o trabalho de Camões (1560), trabalho esse que não se encontra acessível. Neste caso Rodrigues é a fonte secundária e Camões a fonte primária. A referência seria “... (Camões, 1560 citado por Rodrigues, 2020) ou, caso não tenha se acesso à data da fonte primária: "no trabalho de Camões (citado por Rodrigues, 2020)". Apenas o trabalho de Rodrigues (2020) irá surgir no capítulo de referências. A Tabela 9 ilustra os diferentes tipos de citações no texto. 
NORMAS DE ESCRITA CIENTÍFICA (APA, 7a EDIÇÃO)

\section{Tabela 9}

Citações Narrativas e Não Narrativas (i.e., entre parênteses)

\begin{tabular}{lcc}
\hline & Citação narrativa ${ }^{\text {a }}$ & Citação não narrativa \\
\hline Um autor & Prada (2020) & (Prada, 2020) \\
Dois autores & Prada e Garrido (2020) & (Prada \& Garrido, 2020) \\
Três ou mais autores & Prada et al. (2020) & (Prada et al., 2020) \\
$\begin{array}{l}\text { Trabalho de um grupo identificado } \\
\text { com uma sigla }\end{array}$ & Instituto Nacional de & (Instituto Nacional de \\
$\begin{array}{l}\text { Trabalho de um grupo não } \\
\text { identificado com uma sigla }\end{array}$ & Estatística (INE, 2020) & Estatística [INE] 2020) \\
\hline
\end{tabular}

${ }^{a}$ Citações em que o nome do(s) autor(es) surge(m) integrado(s) no texto, fora de parênteses. ${ }^{b} \mathrm{~A}$ descrição da sigla ou acrónimo apenas é apresentada na primeira vez que é mencionada. No exemplo do Instituto Nacional de Estatística, a citação subsequente seria “...INE (2020)" ou “...(INE, 2020)”.

Apesar de a paráfrase ser a forma mais comum de citação, por vezes podemos optar por fazer uma reprodução exata do excerto de um texto previamente publicado. A apresentação de uma citação literal exige alguns cuidados e deve ser usada apenas em casos excecionais. Podemos recorrer à citação literal, por exemplo, quando queremos apresentar a formulação exata de uma definição, quando queremos reproduzir uma instrução ou comentar a formulação de uma ideia ou conceito. As citações devem reproduzir de forma fiel o texto original. Fonte e citação devem ser em tudo semelhantes, incluindo nas palavras usadas e na pontuação. Mesmo as eventuais incorreções devem ser reproduzidas. Neste caso, poderá ser incluída a expressão [sic], o que significa que as palavras do autor são apresentadas textualmente. Esta expressão surge entre parênteses retos e em itálico. A citação literal vem acompanhada pelo(s) apelido(s) do autor(es), pela data da publicação e pelo número da página ou páginas onde surge a citação no texto original. Se a citação surge numa única página no original, deve usar-se a abreviatura "p.", caso sejam várias páginas a abreviatura "pp.". Se forem contínuas, as páginas são separadas por travessão, caso contrário são separadas por vírgula (ver exemplos fictícios que se seguem):

Tal como diz Variações, "quando a cabeça não tem juízo, o corpo é que paga" (1983, p.3)... Tal como diz Variações, "quando a cabeça não tem juízo, o corpo é que paga" (1983, p.3-4)... Tal como diz Variações, "quando a cabeça não tem juízo, o corpo é que paga" $(1983$, p.3,5)...

Algumas adaptações são possíveis para garantir a integração da citação no texto: 
1. A citação pode ser iniciada com letra maiúscula ou minúscula, dependendo da sua posição na frase;

2. A pontuação no final da citação pode ser alterada;

3. Aspas simples podem ser transformadas em aspas duplas;

4. Podem ser omitidas notas de rodapé eventualmente incluídas no texto original.

Qualquer outra alteração terá de ser tornada explícita. Por exemplo, se uma parte da citação for omitida, essa omissão deverá ser assinalada com três pontos separados com espaços, apresentados entre parênteses ( . . . ). Devem usar-se quatro pontos entre parênteses, separados por espaços, para assinalar a omissão de texto entre frases $($. . . . ). Se for incluído texto na citação, por exemplo para a tornar mais fácil de compreender ou para tornar o conteúdo mais claro, este deve ser apresentado entre parênteses retos. Para dar ênfase a uma parte da citação deve usar-se o itálico e, imediatamente após o itálico, escrever [ênfase adicionada]. A Figura 4 ilustra diferentes modos de apresentar uma citação literal salientando as regras inerentes.

\section{Figura 4}

Modos de Apresentação de Citações Literais

\section{Quando a citação não faz parte da narrativa}

A atração romântica interliga-se em grande parte com o estilo primário de amor "eros" ( ... ) definido como "a state of intense longing for union with another" (Hatfield \& Rapson, 1994, p. 93).

\section{Quando a citação faz parte da narrativa e sucede o texto reproduzido:}

A atração romântica interliga-se em grande parte com o estilo primário de amor "eros" ( ... ) definido como "a state of intense longing for union with another" por Hatfield e Rapson (1994, p. 93).

Em 1994, Hatfield e Rapson colocam a seguinte questão: será o amor romântico “a state of intense longing for union with another?" (p. 93). 
NORMAS DE ESCRITA CIENTÍFICA (APA, 7ạ EDIÇÃO)

A reprodução de excertos com menos de 40 palavras deve ser feita entre aspas e integrada no texto, tal como se pode observar nos exemplos da Figura 4. Se o excerto a citar tiver 40 ou mais palavras, deve ser apresentado como um bloco. Este texto não é apresentado entre aspas, surge numa nova linha (e não integrado no texto) e todo o bloco de texto tem um avanço de $1.27 \mathrm{~cm}$. A citação pode ser feita entre parênteses no final do bloco, depois da pontuação, ou de forma narrativa, seguindo as normas já apresentadas. O exemplo abaixo apresenta duas formas de uma citação literal com mais de 40 palavras.

Prada et al. (2014) selecionaram um conjunto de imagens de animais, com a finalidade de testar as normas de valência, familiaridade, medo, nojo e perigosidade. O objetivo dos autores consistiu em:

... incluir imagens de animais passíveis de serem encontrados num contexto doméstico (i.e., abelha, osga, centopeia, rato e barata) ou não doméstico (i.e., cobra, escorpião, lagarto, morcego e tarântula) com vista a poder manipular mais facilmente o contexto onde os estímulos são apresentados, bem como o grau de familiaridade com os estímulos (p. 43).

Em alternativa, a citação pode ser apresentada da seguinte forma:

Foi selecionado um conjunto de imagens de animais, com a finalidade de testar as normas de valência, familiaridade, medo, nojo e perigosidade. O objetivo dos autores consistiu em:

... incluir imagens de animais passíveis de serem encontrados num contexto doméstico (i.e., abelha, osga, centopeia, rato e barata) ou não doméstico (i.e., cobra, escorpião, lagarto, morcego e tarântula) com vista a poder manipular mais facilmente o contexto onde os estímulos são apresentados, bem como o grau de familiaridade com os estímulos (Prada et al., 2014, p. 43).

\section{Normas para Referências Bibliográficas}

\section{Lista de Referências}

A secção onde são listadas as referências bibliográficas é construída em estreita articulação com o conjunto de citações apresentado ao longo do texto. Para os leitores de um trabalho académico ou científico, a informação detalhada que surge na lista de referências permite identificar e localizar a fonte de informação original e assim aprofundar os temas em análise.

A lista de referências inicia-se numa nova página, após o corpo do texto. 0 título "Referências" surge no topo da página, iniciado por maiúscula, negrito e centrado (ou seguindo a formatação título Nível 1). Tal como o restante corpo do texto, a página é formatada com espaçamento duplo em todas as entradas da lista. Cada referência corresponde a uma entrada e surge numa linha própria. A primeira linha de cada entrada é alinhada à esquerda e as linhas subsequentes são indentadas, com 
NORMAS DE ESCRITA CIENTÍFICA (APA, 7ạ EDIÇÃO)

um avanço de $1.27 \mathrm{~cm}$ (opção avanço pendente/hanging indentation)4 . A organização da lista obedece a um critério alfabético, em função do apelido do primeiro autor de cada trabalho, como é visível na Figura 5.

\section{Figura 5}

Exemplo de Organização de Lista de Referências

\section{Referências}

Avanço Pendente Permite destacar nome do 1은 autor

Beierle, T. C., \& Cayford, J. (2001). Public participation in environmental decisions: Lessons from the case study record (pp. 68-79). Resources for the Future. https://doi.org/10.1017/S175577391300009X

Capozza, D., Andrighetto, L., Di Bernardo, G., \& Falvo, R. (2012). Does status affect intergroup perceptions of humanity? Group Processes and Intergroup Relations, 15, 363-377.

https://doi.org/10.1177/1368430211426733

Organizar várias entradas do mesmo autor (e.g., Fiske):

Ordem cronológica do mais antigo para o mais recente (e.g., 2009 antes de 2013) único autor, seguidas das referências com coautores (ordenação alfabética dos autores subsequentes - e.g., Borgida antes de Cuddy)

Amnå, E., \& Ekman, J. (2013). Standby citizens: Diverse faces of political passivity. European Political Science Review, 6(2), 261-281. https://doi.org/10.1017/S175577391300009X

T. (2009). From dehumanization and objectification to rehumanization. Annals of the New York Academy of Sciences, 1167(1), 31-34. https://doi.org/10.1111/j.1749-6632.2009.04544.x

Fiske, S. T. (2013). Varieties of (de)humanization: Divided by competition and status. In S. J. Gervais (Ed.), Objectification and (de)humanization: 60th Nebraska symposium on motivation (pp. 53-71). Springer. https://doi.org/10.1007/978-1-4614-6959-9

Fiske S. T., \& Borgida, E. (2008). Providing expert knowledge in an adversarial context: Social cognitive science in employment discrimination cases. Annual Review of Law and Social Science, 4, 123-148. https://doi.org/10.1146/annurev.lawsocsci.4.110707.172350

Fiske, S. T., Cuddy, A. J., Glick, P., \& Xu, J. (2002). A model of (often mixed) stereotype content: Competence and warmth respectively follow from perceived status and competition. Journal of Personality and Social Psychology, 82(6), 878-902. https://doi.org/10.1037/0022-3514.82.6.878

Cada referência apresenta a informação necessária para identificar, localizar e permitir o acesso às fontes originais. Por esse motivo deve garantir-se que cada trabalho citado corresponde a uma entrada na lista de referências e que o oposto também é verdadeiro, ou seja, todas as

\footnotetext{
${ }^{4}$ Num processador de texto como o Microsoft Word deverá selecionar "Opções de Espaçamento entre Linhas" e, na seç̧ão Avanço, escolher a opção "Pendente". Automaticamente será definido que o avanço será de 1.25 ou $1.27 \mathrm{~cm}$ (este último corresponde exatamente a 0.5 inches definido pela APA).
} 
NORMAS DE ESCRITA CIENTÍFICA (APA, 7ạ EDIÇÃO)

referências correspondem a trabalhos citados. Esta seç̧ão dos trabalhos científicos rege-se por um conjunto de regras relativamente rígidas, que estipulam a formatação de cada tipo de entrada e a organização das diferentes entradas na lista.

O Manual da APA (2020) divide as referências em quatro grandes grupos (ver Capítulo 10 "Reference Examples", pp. 313-354): documentos textuais (grupo 1); bases de dados, software e testes psicológicos (grupo 2); audiovisuais e média (grupo 3); e média online/redes sociais (grupo 4). Dentro de cada grupo existem variações que compõem mais de 100 tipos de referências. Adicionalmente, são ainda definidas recomendações para referenciar documentos legais (e.g., legislação, patentes, tratados - Capítulo 11 “Legal References”, pp. 355-370). Não é possível delinear uma regra geral que se aplique a todas as tipologias e as regras relativas a cada tipo de documento indicam que informação será apresentada. Comummente são incluídas informações relativas à autoria, data de publicação e ao título do documento, mas podem ser requeridas muitas outras informações. As normas ditam ainda a ordem da informação, a pontuação e a formatação do texto (e.g., utilização de itálico).

A enorme quantidade de normas e variações não nos permite apresentá-las de forma exaustiva. De seguida são apresentadas as regras para a composição das referências dos tipos de fontes que consideramos surgir mais frequentemente: (a) publicações periódicas; (b) livros, capítulos de livros e entradas em livros de referência; (c) dissertações ou teses; (d) conferências; (e) e média online/redes sociais.

\section{Publicações Periódicas}

As publicações periódicas definem-se como fontes com edição regular tais como as revistas científicas (scientific journals - e.g., Journal of Experimental Psychology), e as publicações da comunicação social como os jornais e revistas (e.g., Público e Visão, respetivamente)=

Todas as referências relativas a publicações periódicas devem conter os seguintes elementos: indicação do nome do(s) autor(es), que pode igualmente ser um grupo (e.g., INE) ou a designação de um website; a data da publicação; o título do documento; informação da publicação 
periódica e, se disponível, o DOI ou URL. Seguem-se alguns exemplos de citações de publicações periódicas.

A forma geral de referência de um artigo científico e respetiva formatação é apresentada na

Figura 6.

\section{Figura 6}

\section{Referência de Artigo Científico com DOI}

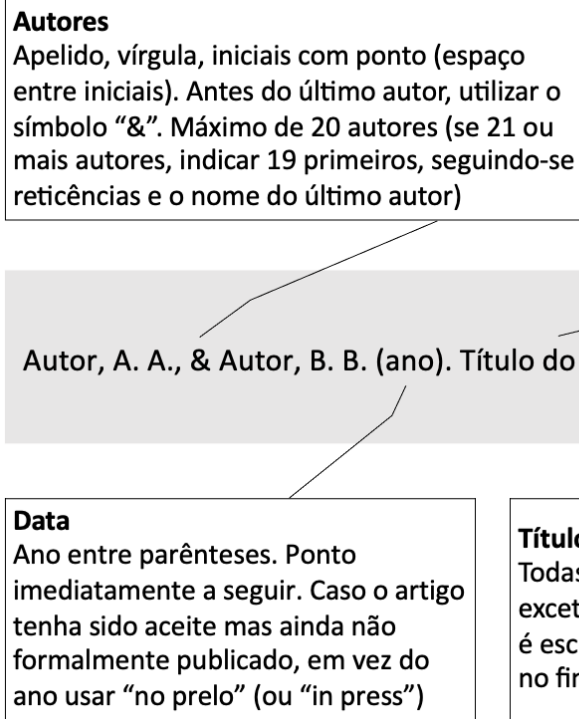

Data

Ano entre parênteses. Ponto imediatamente a seguir. Caso o artigo tenha sido aceite mas ainda não formalmente publicado, em vez do ano usar "no prelo" (ou "in press")

\section{Título do artigo}

Apenas 1a letra da 1a palavra de cada frase é escrita em maiúscula. Os nomes próprios são igualmente iniciados com uma maiúscula. Termina com ponto

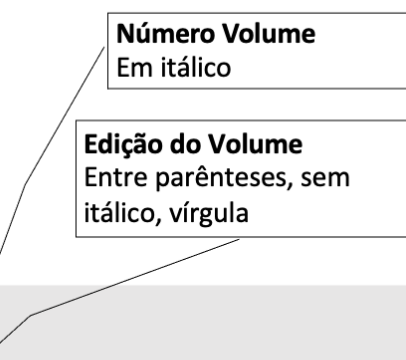

$X X(x)$, pp-pp. https://doi.org/XXXX

Exemplo 1

Rodrigues, D. L., Lopes, D., Pereira, M., Prada, M., \& Garrido, M. V. (2020). Predictors of condomless sex and sexual health behaviors in a sample of Portuguese single adults. Journal of Sexual Medicine, 17(1), 26-36. https://doi.org/10.1016/j.jsxm.2019.10.005

A referência anterior (Exemplo 1) indica que o artigo "Predictors of Condomless Sex and Sexual Health Behaviors in a Sample of Portuguese Single Adults", escrito por D. L. Rodrigues, D. Lopes, M. Pereira, M. Prada e M. V. Garrido, foi publicado em 2020 na revista científica "Journal of Sexual Medicine" e que o podemos encontrar no volume número 17 desta publicação, na edição número 1 desse volume, nas páginas 26 a 36. Se seguirmos a hiperligação apresentada iremos chegar ao documento citado.

O Exemplo 2 ilustra a referência de um trabalho com mais de 20 autores (salientamos que neste caso não se inclui " $\&$ " antes do último autor). 
Exemplo 2

Pegion, K., Kirtman, B. P., Becker, E., Collins, D. C., LaJoie, E., Burgman, R., Bell, R., DelSole, R., Min, D., Zhu, Y., Li, W., Sinsky, E., Guan, H., Gottschalck, J., Metzger, E. J., Barton, N. P., Achuthavarier, D., Marshak, J., Koster, R., . . . $\mathrm{Kim}, \mathrm{H}$. (2019). The subseasonal experiment (SubX): A multimodel subseasonal prediction experiment. Bulletin of the American Meteorological Society, 100(10), 2043-2061. https://doi.org/10.1175/BAMS-D-18-0270.1

A referência geral para um artigo de jornal, revista ou post de blogue consultado online está representada na Figura 7.

\section{Figura 7}

Referência de Artigo de Jornal, Revista ou Post de Blog Consultado Online

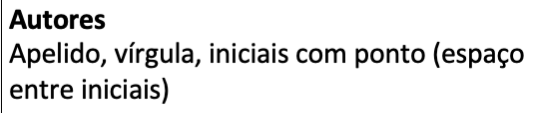

\section{Título do artigo}

Apenas 1a letra da 1a palavra de cada frase é escrita em maiúscula. Os nomes próprios são igualmente iniciados com uma maiúscula. Termina com ponto

Autor, A. A., \& Autor, B. B. (ano, dia mês). Título do artigo. Publicação. URL

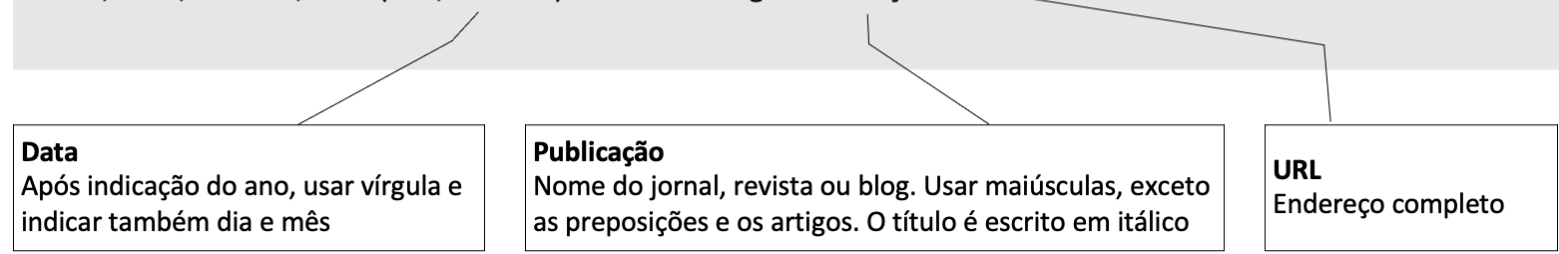

Exemplo 3

Martins, C. (2020, 7 de novembro). Joe Biden: Os títulos da vitória. Expresso.

https://expresso.pt/internacional/eleicoes-americanas/2020-11-07-Joe-Biden-os-titulos-da-vitoria

O Exemplo 3 refere-se ao artigo "Joe Biden: Os Títulos da Vitória", publicado no

semanário Expresso no dia 7 de novembro de 2020 e escrito por Christiana Martins. Note-se

que a estrutura da referência é muito semelhante à anterior, no entanto, a data é

apresentada com maior detalhe, acrescentando-se ao ano o dia e o mês da publicação.

Como se trata de um artigo online, não é incluída informação do número de páginas. 0

Exemplo 4 diz respeito a um post e segue uma estrutura semelhante.

\section{Exemplo 4}

Franco, M. (2020, 17 de Julho). 5 ways to make new friends when you're stuck at home. Psychology Today. https://www.psychologytoday.com/intl/blog/platonic-love/202007/5-ways-make-new-friends-when-youre-stuckhome 
NORMAS DE ESCRITA CIENTÍFICA (APA, 7ạ EDIÇÃO)

\section{Livros, Livros Editados e Capítulos de Livros}

Esta secção apresenta as normas de referenciação de livros ou manuais, escritos por um ou por vários autores, e as normas relativas a livros editados, onde existe um ou mais responsáveis pela organização do livro e diversos autores para os diferentes capítulos. Existindo variações em função do tipo de publicação e do seu suporte (físico ou digital), as referências de livros ou de livros editados incluem obrigatoriamente o nome do(s) autor(es) ou dos organizadores, o ano, o título e a fonte, seja esta física ou digital. A Figura 8 refere-se à notação específica de livros com autor (8A) e de livros editados (8B).

\section{Figura 8}

Referência de Livros: Autores (8A) ou Editores (8B)

\begin{tabular}{|c|c|c|c|c|c|}
\hline $\begin{array}{l}\text { Autores ou Editores } \\
\text { Apelido, vírgula, iniciais com } \\
\text { ponto (espaço entre iniciais) }\end{array}$ & $\begin{array}{l}\text { Data } \\
\text { Ano entre parênteses. } \\
\text { Ponto a seguir }\end{array}$ & \multicolumn{2}{|c|}{ 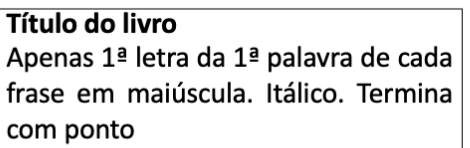 } & \multicolumn{2}{|c|}{$\begin{array}{l}\text { Edição } \\
\text { Número da edição (exceto } \\
\text { se for a 1a) seguido de "ed." }\end{array}$} \\
\hline $\begin{array}{l}\text { Autor, A. A., \& A } \\
\text { Editor, E. E., \& E }\end{array}$ & \multicolumn{5}{|c|}{ Autor, A. A., \& Autor, B. B. (ano). Título do livro (x ed.). Editora. DOI ou URL } \\
\hline \multicolumn{3}{|c|}{$\begin{array}{l}\text { Eds. } \\
\text { Abreviatura de Editores (com maiúscula, entre parênteses, termina } \\
\text { com ponto) é o que indica que se trata de um livro editado }\end{array}$} & \multicolumn{2}{|c|}{$\begin{array}{l}\text { Editora/Publisher } \\
\text { Empresa ou organização } \\
\text { que publicou o livro }\end{array}$} & $\begin{array}{l}\text { DOI ou URL } \\
\text { (Se disponível) }\end{array}$ \\
\hline
\end{tabular}

Exemplo 5

Lima, M. L. (2018). Nós e os outros: O poder dos laços sociais. Fundação Francisco Manuel dos Santos.

Exemplo 6

Vala, J., \& Monteiro, M. B. (Eds.). (2017). Psicologia social (10a ed.). Fundação Calouste Gulbenkian.

O Exemplo 5 refere-se ao livro com o título "Nós e os Outros: O Poder dos Laços Sociais" da autoria de M. L. Lima e publicado em 2018 pela Fundação Francisco Manuel dos Santos.

Em vez de um livro escrito integralmente por um autor (ou vários), podemos querer apresentar a referência de um livro com editores, ou seja, um livro onde uma ou várias pessoas ou um grupo reuniram os contributos de diversos autores numa única obra. Como se pode observar no 
Exemplo 6, J. Vala e M. B. Monteiro são os editores da décima edição do livro "Psicologia Social", editado em 2017 pela Fundação Calouste Gulbenkian.

Por vezes apenas nos debruçamos sobre um capítulo de um livro e não sobre todo o livro. Caso tenha consultado o capítulo de um livro sem editores (Exemplo 5), deve citar o livro na sua totalidade e apenas no texto poderá remeter para esse capítulo. No entanto, as citações de capítulos de livro editados possuem uma forma de referência específica (ver Figura 9).

\section{Figura 9}

Referência de Capítulo de Livro Editado

\begin{tabular}{|c|c|c|}
\hline $\begin{array}{l}\text { Título do capítulo } \\
\text { Apenas } 1 \text { a letra da 1a palavra de cada frase é } \\
\text { escrita em maiúscula. Termina com ponto. }\end{array}$ & $\begin{array}{l}\text { In ou Em } \\
\text { Precede o nome } \\
\text { dos editores }\end{array}$ & $\begin{array}{l}\text { Título do livro } \\
\text { Apenas 1ạ letra da 1a palavra de cada frase } \\
\text { é escrita em maiúscula. Itálico }\end{array}$ \\
\hline Autor, A. A., \& Autor, B. B. (ano). Título do & ulo. In E. E. Editor \& F. F. E & ro $(x$ ed., $\mathrm{pp}$ \\
\hline \multicolumn{3}{|l|}{ Editora. DOI ou URL } \\
\hline $\begin{array}{l}\text { Editores } \\
\text { Iniciais precedem apelido. Deve existir um } \\
\text { espaço entre as iniciais. Terminar com a } \\
\text { menção (Eds.), seguida de vírgula }\end{array}$ & $\begin{array}{l}\text { Edição } \\
\text { Número da edição (exceto se } \\
\text { for a 1â) seguido de "ed." } \\
\text { seguido de vírgula }\end{array}$ & $\begin{array}{l}\text { Páginas do capítulo } \\
\text { Começar com a menção “pp”. E depois } \\
\text { indicar no de página inicial, hífen, no de } \\
\text { página final }\end{array}$ \\
\hline
\end{tabular}

A Figura 9 ilustra as especificidades desta forma de referência, nomeadamente que o nome que surge no início da referência é o do(s) autor(es) do capítulo e não o dos editores. Da mesma forma, o título referido depois da data é o título do capítulo referenciado. Só de seguida são apresentados os nomes dos editores do livro e o título do livro (ver Exemplo 7).

\section{Exemplo 7}

Marques, J., Páez, D. \& Pinto, I. (2017). Estereótipos: Antecedentes e consequências das crenças sobre os grupos. Em J. Vala, \& M. B. Monteiro (Eds.), Psicologia social (10a ed., pp. 435-492). Fundação Calouste Gulbenkian.

A referência representada no Exemplo 7 pertence ao capítulo "Estereótipos: Antecedentes e Consequências das Crenças sobre os Grupos", escrito por J. Marques, D. Páez e I. Pinto e publicado no livro editado "Psicologia Social", já anteriormente referido.

Muitos trabalhos académicos implicam a definição de conceitos. Neste caso podemos optar por consultar um dicionário temático. Hoje em dia, podemos encontrar este tipo de publicação em 
NORMAS DE ESCRITA CIENTÍFICA (APA, 7ạ EDIÇÃO)

formato físico, mas também online. Em ambos os casos a referência deve indicar o conceito consultado.

A referência abaixo indica que o termo "stereotype threat" foi consultado no "APA Dictionary of Psychology”, um dicionário de psicologia disponível online. Uma vez que este tipo de dicionário é constantemente atualizado, a data de consulta deve ser incluída na referência (Exemplos 8 e 9 para trabalhos redigidos em português e inglês, respetivamente).

Exemplo 8

American Psychological Association. (s.d.). Stereotype threat. Em APA dictionary of psychology. Retirado a 20 de setembro, 2020, de https://dictionary.apa.org/stereotype-threat

Exemplo 9

American Psychological Association. (n.d.). Stereotype threat. In APA dictionary of psychology. Retrieved september, 20, from https://dictionary.apa.org/stereotype-threat

Não existindo um nome de autor, a referência inclui o nome da editora, a inexistência de data é abreviada como "s.d." ou "n.d." (ou seja, "sem data" ou "no date"), o termo consultado, para além da data na qual a informação foi retirada e a respetiva hiperligação. A referência relativa à mesma entrada no dicionário de psicologia da APA, mas desta vez na versão em papel, apresenta a mesma estrutura, mas com algumas diferenças (Exemplo 10). A referência apresenta a data da publicação e a página. No entanto, como é natural, não apresenta a data da consulta e a hiperligação.

Exemplo 10

American Psychological Association (2015). Stereotype threat. In APA dictionary of psychology (2 ${ }^{\text {nd }}$ ed., p. 1031).

\section{Conferências}

Todos os trabalhos apresentados em conferências podem ser consultados e referenciados, incluindo apresentações orais, sessões de pósteres e apresentações em simpósios. O acesso posterior a esta informação é feito através da publicação das atas (proceedings) de conferências em formato de livro ou de publicação periódica. Para a referenciação dos documentos formalmente publicados aplicam-se as normas já referidas. A referenciação de comunicações não publicadas segue o formato definido na Figura 10. 
NORMAS DE ESCRITA CIENTÍFICA (APA, 7ạ EDIÇÃO)

\section{Figura 10}

Referência de Comunicação Não Publicada

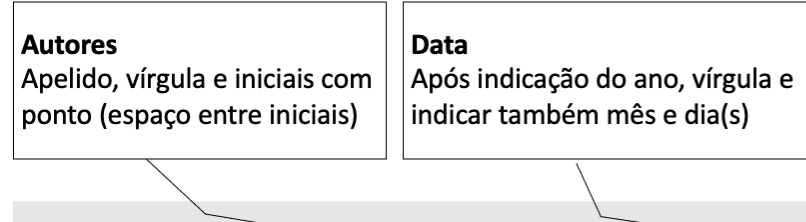

Título da comunicação

Apenas 1a letra da 1a palavra de cada frase é escrita em maiúscula. Os nomes próprios são igualmente iniciados com uma maiúscula. Termina com ponto. Itálico

Apresentador, A. A. \& Apresentador B., B. (ano, mês dia). Título da comunicação [Apresentação oral ou

Apresentação póster/paper presentation or poster presentation]. Nome da Conferência, Local. DOI ou URL

Tipo de Apresentação

Definir tipo de apresentação entre parênteses retos

\section{Identificação da Conferência}

No nome usar maiúsculas, exceto as preposições e os artigos. Identificar cidade e país
DOI ou URL

(Se disponível)

\section{Exemplo 11}

Camilo, C, Lima, M. L. \& Rimé, B. (2014, outubro 20-24). The role of others: Social sharing of emotion modes and the cognitive and emotional adaptation to threatening cancer information [Apresentação oral]. 16th World Congress of Psycho-Oncology and Psychosocial Academy, Lisboa. https://doi.org/10.1111/i.10991611.2014.3694

Os simpósios são coordenados/organizados por uma ou mais pessoas (coordenador ou chair). Assim, a contribuição num simpósio assume o formato definido na Figura 11 (ver Exemplo 12).

\section{Figura 11}

\section{Referência de Contribuição em Simpósio}

\author{
Título da comunicação \\ Apenas 1a letra da 1a palavra de cada frase é escrita em maiúscula. Os \\ nomes próprios são igualmente iniciados com uma maiúscula. Termina \\ com ponto. Sem Itálico
}

\section{Coordenador do Simpósio}

Iniciais precedem apelido. Espaço entre as

iniciais

Apresentador, A. A. \& Apresentador B., B. (ano, mês dia). Título da comunicação. In C. C. Coordenador

(Coordenador/Chair), Título do simpósio [Simpósio/Symposium]. Nome da conferência, Local. DOI ou URL

Título do Simpósio

Apenas 1 ạ letra da $1 \mathfrak{a}$ palavra de cada frase é escrita em maiúscula. Itálico
Identificação do tipo de comunicação

Definir que se trata de contribuição em simpósio entre parêntesis retos

Nota. Na Figura 11 apenas destacámos os elementos da referência que variam em relação à Figura 10.

\section{Exemplo 12}

Camilo, C., Lima, M. L., \& Rimé, B. (2010, setembro, 22). How to deal with cancer information: The effect of sharing mode on the emotional recovery and illness representation. In B. Rimé (Coordenador), Social sharing of emotions and health: Consequences and antecedents of sharing health related emotions [Simpósio]. 25 th European Health Psychology Society Conference, Creta, Grécia. https://doi.org/10.1080/08870446.2011.617190 
NORMAS DE ESCRITA CIENTÍFICA (APA, 7ạ EDIÇÃO)

\section{Teses ou Dissertações}

As dissertações de mestrado e as teses de doutoramento são uma fonte importante de informação, sobretudo porque apresentam uma visão exaustiva da literatura disponível sobre um determinado tema. Este tipo de documento pode encontrar-se publicado ou não, sendo possível aceder a grande parte das mesmas a partir de bases de dados internacionais (e.g., Pro-Quest Dissertations) ou dos arquivos eletrónicos das próprias universidades (e.g., https://repositorio.ul.pt/, https://repositorio-aberto.up.pt/, https://repositorio.iscte-iul.pt/ - repositórios da Universidade de Lisboa, da Universidade do Porto e do Iscte-Instituto Universitário de Lisboa, respetivamente). A

Figura 12 demonstra a forma de elaborar a referência de dissertações ou teses (ver também, Exemplo 13).

\section{Figura 12}

Referência de Tese ou Dissertação Não Publicada (12A) ou Publicada (12B)

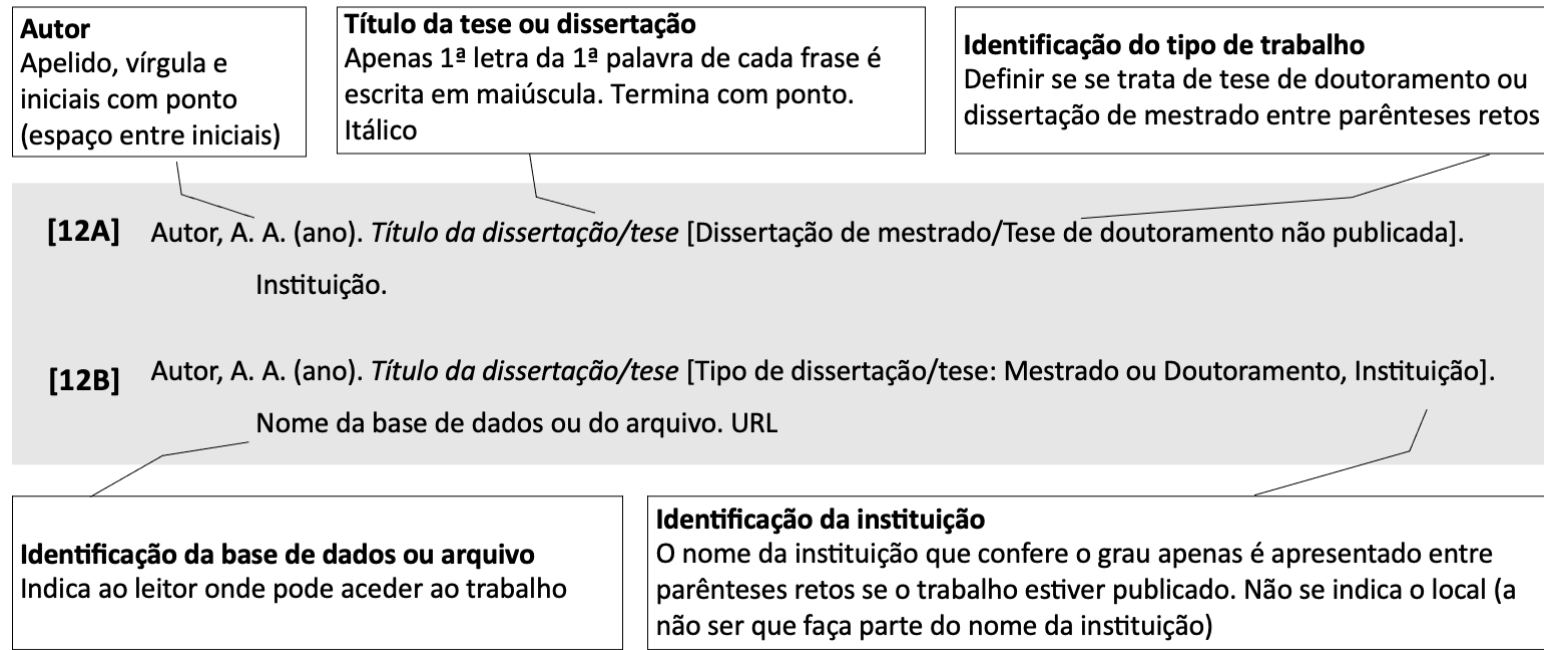

[12A] Autor, A. A. (ano). Título da dissertação/tese [Dissertação de mestrado/Tese de doutoramento não publicada]. Instituição.

[12B] Autor, A. A. (ano). Título da dissertação/tese [Tipo de dissertação/tese: Mestrado ou Doutoramento, Instituição]. Nome da base de dados ou do arquivo. URL

\section{Exemplo 13}

Rodrigues, R. B. (2012). Conflicting social norms and white children's expressions of intergroup racial attitudes: A socionormative developmental model [Tese de doutoramento, Iscte-Instituto Universitário de Lisboa]. Repositório do ISCTE-IUL. https://repositorio.iscte-iul.pt/handle/10071/9947

\section{Média online}

Citar material consultado nas diferentes plataformas da internet é cada vez mais frequente.

A 7̣ edição do manual da APA acompanha esta tendência e apresenta um grande conjunto de normas de referenciação para fontes tão diversas como Twitter, Facebook, Instagram ou mesmo 
NORMAS DE ESCRITA CIENTÍFICA (APA, 7ạ EDIÇÃO)

TikTok. A norma apresentada pode ser adaptada para (quase) todas as redes sociais e segue o formato definido na Figura 13 (ver Exemplo 14).

\section{Figura 13}

Referência de Conteúdo de Redes Sociais

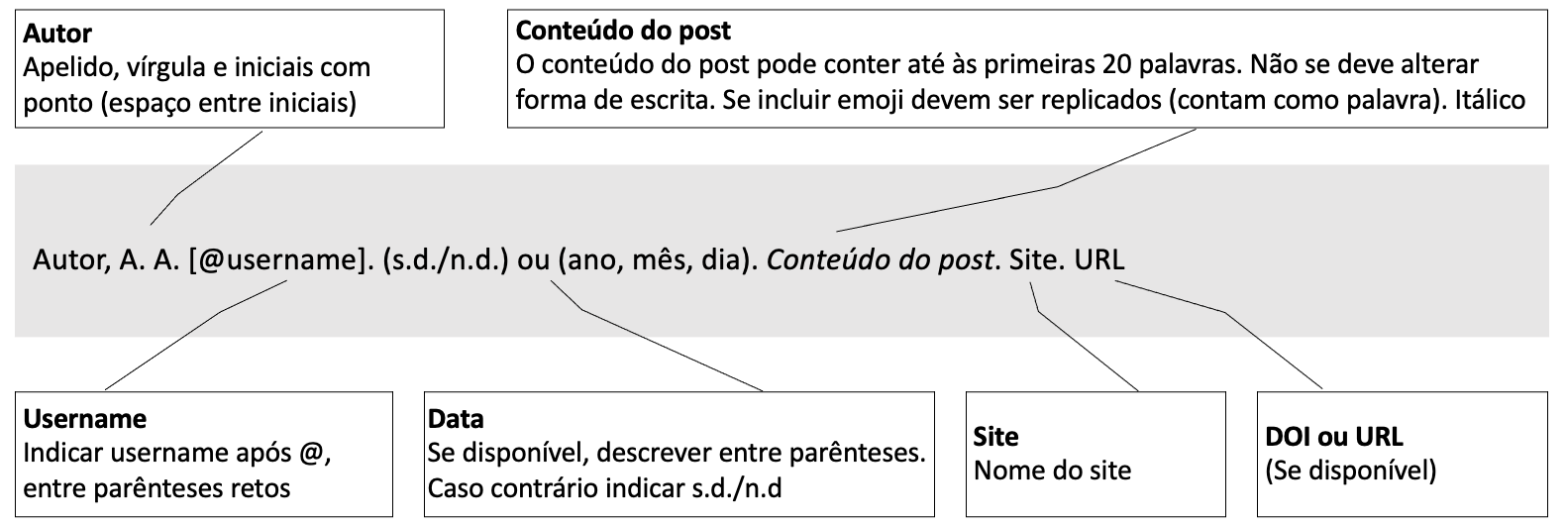

Exemplo 14

Trump, D. J. [@realDonaldTrump]. (2012, October, 22). Everyone knows I am right that Robert Pattinson should dump Kristen Stewart. Twitter. https://twitter.com/realDonaldTrump/status/260482827458592768

\section{Recursos online e software de referências}

Durante a escrita de um texto temos, muitas vezes, de gerir uma quantidade considerável de material bibliográfico. Para ultrapassar as naturais dificuldades de gestão desta informação e prevenir eventuais falhas, podemos recorrer a um conjunto de ferramentas de gestão de referências. Existe uma grande quantidade e variedade de recursos neste campo, sendo que apresentamos apenas alguns exemplos.

Começamos por referir quatro softwares de gestão de referências, aos quais se pode aceder gratuitamente. O Mendeley (https://www.mendeley.com/) e o Zotero (https://www.zotero.org/) são softwares de gestão de referências que permitem importar e organizar automaticamente artigos em formato PDF e as respetivas informações bibliográficas. Ambos permitem integração com outras aplicações (motores de pesquisa e processadores de texto). Por exemplo, ao pesquisar um artigo numa base de dados ou website usando o Google Chrome, é possível gravar a referência facilmente (requerendo apenas a instalação de uma extensão para o efeito). Para além disso, ambos os softwares geram citações no Microsoft Word e criam a lista de referências de acordo com vários 
NORMAS DE ESCRITA CIENTÍFICA (APA, 7ạ EDIÇÃO)

estilos de referências, incluindo o da APA. Apresentam ainda outras funcionalidades, como anotar os artigos e partilhar documentos e listas de referências com outros utilizadores. Para além disso, o Zotero permite atualizar o estilo das referências para a 7ạ edição da APA através das preferências dos documentos. Outra alternativa amplamente conhecida é o Endnote (https://endnote.com/product-details/basic/), cuja versão grátis também possui as funcionalidades essenciais de gestão de referências. Por último, salientamos uma nova ferramenta de gestão de referências - o ReadCube (https://www.readcube.com). Para além das funcionalidades apresentadas pelos restantes softwares, permite encontrar facilmente artigos que são citados no documento que se está a consultar. O ReadCube também guarda as informações de login institucional, para tornar possível o acesso a artigos pagos. Apresenta ainda recomendações de leitura compatíveis com os artigos consultados.

Existe ainda um conjunto de recursos online que facilita a gestão da lista de referências. Um exemplo bem conhecido é a Crossref (www.crossref.org), uma agência de registo de DOI. Esta agência regista metadados bibliográficos e não bibliográficos dos textos científicos, que são tratados de forma a associar as publicações aos autores e às organizações. Estes dados são disponibilizados de diferentes formas e através de várias interfaces, que permitem, para além de outros aspetos, facilitar a gestão de referências e otimizar a pesquisa de literatura. A plataforma requer uma inscrição, no entanto disponibiliza serviços a membros e não membros. Entre os muitos serviços disponíveis, a Crossref permite fazer a associação entre a ligação apresentada na referência e o documento completo. Para fazer esta ligação é necessário que as referências apresentem os DOI na forma de URL, bem como a exportação da referência no formato desejado.

Finalmente, muitas das bases de dados consultadas durante a pesquisa bibliográfica, como a Scielo, a Web of Science (WoS), ou a Ebsco, permitem fazer a exportação direta das referências consultadas, já no formato desejado. Isto significa que, à medida que é feito o levantamento do material bibliográfico, podemos imediatamente constituir uma lista de referências preliminar, que poderá ser revista no final. Por exemplo, um aspeto que é comum ter de ser corrigido manualmente 
NORMAS DE ESCRITA CIENTÍFICA (APA, 7ạ EDIÇÃO)

na base de dados do software de gestão de referências é o título de artigos científicos, que, com frequência, é exportado (erradamente) com todas as palavras em maiúsculas.

É de reforçar que a informação aqui apresentada é apenas exemplificativa e uma pequena parte da grande quantidade de recursos acessíveis a quem necessita de elaborar a sua lista de referências de acordo com as normas apresentadas no novo manual da APA. Uma vez que, como vimos, estas ferramentas não são isentas de erro, é essencial conhecer as normas e, sempre que necessário, consultá-las.

\section{Conclusão}

Neste trabalho, procurámos sistematizar as principais recomendações de escrita científica definidas na nova edição do manual da APA. Os aspetos que identificámos como centrais são aqueles que, com base na nossa experiência enquanto docentes e investigadores, surgem mais frequentemente. Adicionalmente, procurámos adaptar as recomendações para a língua portuguesa, tendo em consideração se a regra contribui (ou não) para melhorar a legibilidade do texto (e.g., a adoção da notação de casas decimais através de ponto em vez de vírgula é útil porque facilita a leitura de resultados, uma vez que indicadores estatísticos como médias e desvios-padrão devem ser separados por vírgulas). Com vista a assegurar que se utiliza a formatação correta, sugerimos a criação de um modelo (template) no processador de texto (e.g., Microsoft Word) que contemple as principais normas de formatação APA (e.g., definição do sistema de títulos).

Ainda assim, uma vez que o presente artigo constitui uma síntese comentada, a sua leitura não substitui a consulta do manual (APA, 2020). Por um lado, o manual inclui capítulos que discutem aspetos inerentes a boas práticas de investigação e de publicação que não foram aqui abordados. Enquanto fontes complementares em língua portuguesa, sugerimos a leitura de Arriaga e Sales (2016) sobre planeamento de investigação, de L. Garcia-Marques e Garcia-Marques (2016) sobre pensamento crítico, e de Lopes e Pinto (2016) sobre metodologia. Sobre divulgação científica, sugerimos a leitura de Ferreira e Santos (2016) e de Prada e Rodrigues (2016). Por outro lado, mesmo no que diz respeito a recomendações mais concretas ao nível de referências bibliográficas, 
NORMAS DE ESCRITA CIENTÍFICA (APA, 7ạ EDIÇÃO)

não é possível sistematizar todos os casos definidos no manual. Assim, por exemplo, para citar um material menos comum (e.g., obra de arte), poderá ser necessário consultar o manual (ou o blog do estilo APA - https://apastyle.apa.org/blog) com vista a perceber que elementos são requeridos (e.g., nome do artista, museu em que se encontra) e como devem ser formatados. Destacamos ainda que a versão atual deste manual é mais fácil de consultar, contendo mais exemplos das recomendações apresentadas. À semelhança de algumas versões anteriores, a 7ạ edição inclui manuscritos ilustrativos das principais regras ("Sample Professional Paper", pp. 50-60; "Sample Student Paper", pp. 61-70). Em muitos casos, observamos também maior simplificação das recomendações (e.g., possibilidade de abreviar autoria em todos os trabalhos com três ou mais autores desde a primeira citação no texto; eliminação da necessidade de identificar em que local um livro foi publicado). Ao fornecer aos estudantes e investigadores orientações relativamente aos aspetos formais da escrita científica, pretendemos com este trabalho facilitar a escrita de trabalhos científicos, maximizando a eficácia da transmissão do conteúdo. O domínio destas orientações requer treino porque, como será agora evidente, "o Diabo está nos detalhes".

\section{Referências}

APA. (2010). Publication manual of the American Psychological Association (6th ed.).

APA. (2020). Publication manual of the American Psychological Association (7th ed.). https://doi.org/10.1037/0000165-000

Arriaga, P., \& Sales, C. M. D. (2016). Como planear a investigação? In M. V. Garrido \& M. Prada (Eds.), Manual de competências académicas (pp. 245-280). Sílabo.

Bentley, M., Peerenboom, C. A., Hodge, F. W., Passano, E. B., Warren, H. C., \& Washburn, M. F. (1929). Instructions in regard to preparation of manuscript. Psychological Bulletin, 26(2), 57-

\section{3. https://doi.org/10.1037/h0071487}

Ferreira, M. B., \& Santos, A. S. (2016). Divulgação científica: Preparação de relatórios, projetos ou artigos científicos. In M. V. Garrido \& M. Prada (Eds.), Manual de competências académicas (pp. 343-374). Sílabo. 
NORMAS DE ESCRITA CIENTÍFICA (APA, 7ạ EDIÇÃO)

Field, A. (2017). Discovering statistics using IBM SPSS statistics (5th ed.). Sage.

Garcia-Marques, L., \& Garcia-Marques, T. (2016). Pensamento crítico: Antes de se aprender a testar ideias é preciso aprender a ter ideias. In M. V. Garrido \& M. Prada (Eds.), Manual de competências académicas (pp. 223-244). Sílabo.

Marôco, J. (2018). Análise estatística com o SPSS Statistics (70 ed.). ReportNumber.

Moleiro, C., \& Collins, E. (2016). Ética em contexto académico. In M. V. Garrido \& M. Prada (Eds.), Manual de competências académicas (pp. 193-219). Sílabo.

Prada, M., \& Garrido, M. V. (2013). Conhecer as regras do jogo: Uma introdução às normas para escrita científica da American Psychological Association. Psicologia, 27(2), 107-143.

Prada, M., \& Rodrigues, D. L. (2016). Divulgação científica: Desenvolvimento e apresentação de comunicações em formato oral e póster. In M. V. Garrido \& M. Prada (Eds.), Manual de competências académicas (pp. 375-404). Sílabo. 
NORMAS DE ESCRITA CIENTÍFICA (APA, 7ạ EDIÇÃO)

Anexo

Principais Diferenças Entre a $6^{\underline{a}}$ e a $7 \underline{a}$ edição do Manual da APA

\begin{tabular}{|c|c|c|}
\hline & APA 6ạ edição (2010) & APA 7ạ edição (2020) \\
\hline \multicolumn{3}{|l|}{ Formatação } \\
\hline $\begin{array}{l}\text { Tipos de letra } \\
\text { (pontos) }\end{array}$ & $\begin{array}{l}\text { Apenas dois tipos de letra recomendados: } \\
\text { Arial (11) } \\
\text { Times New Roman (12) }\end{array}$ & $\begin{array}{l}\text { Maior flexibilidade relativamente aos tipos } \\
\text { de letra: } \\
\text { Lucida Sans Unicode (10) } \\
\text { Calibri (11) } \\
\text { Arial (11) } \\
\text { Times New Roman (12) } \\
\text { Georgia (11) }\end{array}$ \\
\hline $\begin{array}{l}\text { Cabeçalho } \\
\text { (Running } \\
\text { Head) }\end{array}$ & $\begin{array}{l}\text { Na página de título deveria ser apresentado } \\
\text { um cabeçalho com o título abreviado do } \\
\text { manuscrito precedido pela expressão } \\
\text { “RUNNING HEAD” (nas restantes páginas } \\
\text { apenas o título abreviado) } \\
\text { e.g., } \\
\text { RUNNING HEAD: EMOJI NA COMUNICAÇÃO } \\
\text { ENTRE MARCAS E CONSUMIDOR }\end{array}$ & $\begin{array}{l}\text { Apenas o título abreviado do manuscrito } \\
\text { deve ser incluído } \\
\text { e.g., } \\
\text { EMOJI NA COMUNICAÇÃO ENTRE MARCAS E } \\
\text { CONSUMIDOR }\end{array}$ \\
\hline
\end{tabular}

Níveis de

título

Consultar síntese da versão atual na Tabela 8 e ilustração na Figura 2.

Títulos e Posição da identificação numérica e título numeração de distinta: Acima da tabela e abaixo da figura.

tabelas e A formatação também foi alterada.

figuras

Identificação numérica e título na mesma posição: Acima da tabela e da figura.

Formatação (ambos os casos):

Identificação numérica numa linha (negrito), Título (itálico e title case) na linha seguinte, espaçamento duplo.

Citações no Texto

Primeira Todos os autores apresentados na 1a citação Abreviação possível desde a 1a citação

citação de (apenas trabalhos com 6 ou mais autores

trabalhos com poderiam ser abreviados desde a primeira

três ou mais vez em que eram mencionados) e.g.,

autores $\quad$ e.g., $\quad$ Prada, Garrido, \& Rodrigues (2016)

(Prada, Garrido, \& Rodrigues, 2016)

Citação em Apenas se indicava a data do trabalho

Prada et al. (2016)

(Prada et al., 2016)

segunda mão consultado (fonte secundária, Y) e não da

Se possível, deve indicar-se a data da fonte primária e da fonte secundária (X, 1920,

fonte primária $(X)$

(X, citado por $Y, 2020)$

citado por Y, 2020)

Referências Bibliográficas

Edição do Apenas apresentado quando a numeração Deverá ser sempre incluído

volume (issue da revista não era contínua (i.e., numeração

number) era reiniciada em cada número de um dado volume)

Identificação Inclusão da expressão "Retirado de" ou

do "Retrieved from" antes da apresentação do

armazenamen URL.

to online do e.g.,

documento Mestre, J. (2020, 23 de setembro). O papão

já não mora aqui. Público. Retirado de

URL incluído após identificação do website.

Título da página em itálico.

e.g.,

Mestre, J. (2020, 23 de setembro). O papão

já não mora aqui. Público.

https://www.publico.pt/2020/09/23/culturai

https://www.publico.pt/2020/09/23/culturai 


$\begin{array}{ll}\text { Uniform } & \text { psilon/critica/papao-ja-nao-mora-aqui- } \\ \text { Resource } & 1932315 \\ \text { Locator (URL) } & \\ \begin{array}{l}\text { Identificação } \\ \text { do formato }\end{array} & \text { Incluída } \\ \begin{array}{l}\text { (e.g., PDF), } \\ \text { plataforma e }\end{array} & \text { e.g., } \\ \begin{array}{l}\text { equipamento } \\ \text { (e.g., Kindle) }\end{array} & \text { Bernardes, S. F., \& Carvalhosa, S. F. (2016). } \\ \begin{array}{l}\text { relativo a } \\ \text { ebooks }\end{array} & \begin{array}{l}\text { integração da investigação no Ensino } \\ \text { Superior [Ebook]. Lisboa: ISCTE-IUL. }\end{array} \\ \begin{array}{ll}\text { Digital Object } \\ \text { Identifier }\end{array} & \begin{array}{l}\text { Inclusão da expressão “doi:" } \\ \text { (DOI) }\end{array} \\ & \text { e.g., } \\ & \text { doi: 10.3758/s13428-017-0878-6 }\end{array}$

Localização da Incluída

editora de um e.g.,

livro Garrido, M. V., \& Prada, M. (Eds.) (2016). Manual de competências académicas. Lisboa, PT: Sílabo.

Número máximo de autores incluídos numa referência
7 autores (no caso de trabalhos com mais do que 7 autores, a regra seria introduzir reticências entre o 6a e o último autor) e.g., Żemojtel-Piotrowska, M., Piotrowski, J. P., Osin, E. N., Cieciuch, J., Adams, B. G., Ardi, R., ... Maltby, J. (2018). The mental health continuum-short form: The structure and application for cross-cultural studies-A 38 nation study. Journal of Clinical Psychology, 74(6), 1034-1052. doi:10.1002/jclp.22570

(Nota este artigo contém 44 autores, logo, independentemente da edição do manual da APA, alguns autores serão omitidos). psilon/critica/papao-ja-nao-mora-aqui1932315

Excluída

O nome da editora deve ser apresentado.

e.g.,

Bernardes, S. F., \& Carvalhosa, S. F. (2016).

Manual de práticas pedagógicas de integração da investigação no Ensino Superior. ISCTE-IUL.

O DOI é exibido como um URL "doi.org", em vez de surgir com o prefixo "doi", e é apresentado enquanto hiperligação. Desta forma, quando lemos um dado artigo no website da editora ou mesmo em PDF será, na maioria dos casos, possível aceder diretamente aos artigos citados ao longo do texto.

e.g.,

https://doi.org/10.3758/s13428-017-0878-6

Excluída

e.g.,

Garrido, M. V., \& Prada, M. (Eds.) (2016).

Manual de competências académicas. Sílabo.

20 autores (no caso de trabalhos com mais do que 20 autores, a regra é introduzir reticências entre o 19 e o último autor) e.g., Żemojtel-Piotrowska, M., Piotrowski, J. P., Osin, E. N., Cieciuch, J., Adams, B. G., Ardi, R., Bălţătescu, S., Bogomaz, S., Bhomi, A. L., Clinton, A., de Clunie, G. T., Czarna, A. Z., Esteves, C., Gouveia, V., Halik, M. H. J., Hosseini, A., Khachatryan, N., Kamble, S. V., Kawula, A., ... Maltby, J. (2018). The mental health continuum-short form: The structure and application for cross-cultural studies-A 38 nation study. Journal of Clinical Psychology, 74(6), 1034-1052. https://doi.org/10.1002/jclp.22570 
NORMAS DE ESCRITA CIENTÍFICA (APA, 7ạ EDIÇÃO)

Historial do artigo

Recebido $\quad 11 / 2020$

Aceite 02/2021

Publicado online $\quad 04 / 2021$

Publicado 06/2021 